Journal of Educational

and Psychological Sciences

Volume (4), Issue (37) : 30 Oct 2020

P: 1 - 19

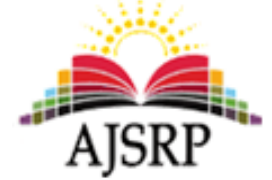

ISSN: 2522-3399
مجلة العلوم

التربوية والنفسية

المجلد (4)، العدد (37) : 30 أكتوبر 2020 م

ص: 19

\title{
Jazan University faculty members' trends toward using the "Blackboard Platform" electronic learning tools in the scientific process in line with the consequences of Coronavirus
}

\author{
Batool AbdElbagi Abdalla Alsaeed \\ Faculty of Education || Jazan University || KSA
}

\begin{abstract}
The study aims at identifying the trends of Jazan University faculty toward employing e-learning tools the Blackboard platform in the educational process, the descriptive approach was used, as the tool was to represent in a resolution distributed to a sample of (90) members of Jazan University faculty teaching staff, and the researcher reached several results:

* the faculty staff employ plaque board tools in simultaneous e-learning and have received an average (4.15 out of 5) (large) grade of scientific and conceptual college student preparation with an average arithmetic (3.88). And (large) while faculty trends toward the application of the plaque board platform were safe and effective in evaluation Student work with an average (2.99) and a (medium) score, while sharing forums, in interactive activities, open-ended tests, was average (2.20) to a small (few) degree. The results also showed that there were no statistically significant differences among the sample population in the trends toward the application of the plaque board tools in the process Teaching staff members according to variables (type/specialization/grade), the researcher made a series of recommendations and proposals; the most important of which are: The need to apply specialized training programs in educational institutions to faculty and students, and to conduct research on the effectiveness of using assessment tools through the Blackboard platform, supporting education E-learning by departments and educational institutions, use the active learning strategies available through the Blackboard platform and the variety of the provision of learning material to the learner, which will lead to its full benefit and increased educational attainment. Intensifying efforts and follow-up by the leadership of e-education and information technology Universities to make full use of.
\end{abstract}

Keywords: Trends, eLearning, Blackboard, faculty, Jazan University. Coronavirus.

$$
\begin{aligned}
& \text { اتجاهات أعضياء هيئة التدرس بجامعة جازان نحو توظيف أدوات التعليم الإلكتروني } \\
& \text { "منصية البلاك بورد" في العملية التعلمية تماشيا مع تداعيات فيروس كورونا } \\
& \text { بتول عبد الباقي عبد الله السعيد } \\
& \text { كلية التربية || جامعة جازان || المملكة العربية السعودية }
\end{aligned}
$$

\footnotetext{
الملخص: هدفت الدراسة إلى التعرف على اتجاهات أعضاء هيئة التدريس بجامعة جازان نحو توظيف أدوات التعليم الإلكتروني منصية

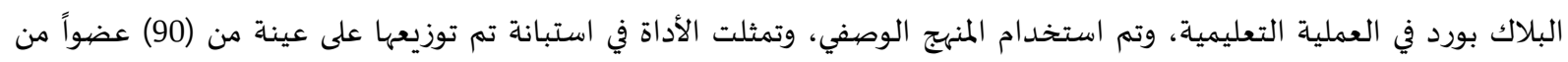
أعضاء هيئة تدريس بجامعة جازان، وتوصلت الباحثة لعدة نتائج أبرزها: يوظف أعضاء هيئة التدريس ادوات منصة البلاك بورد في التعليم الالكتروني المتزامن حصل على متوسط (45.15 من 5) أي بدرجة (كبيرة) إعداد الطالب الجامعي علمياً وفكريا بمتوسط حسابي
} 
(3.88). ودرجة (كبيرة) بينما كانت اتجاهات أعضاء هيئة التدريس نحو توظيف منصاة البلاك بورد منصاة آمنة وفعالة في تقييم أعمال

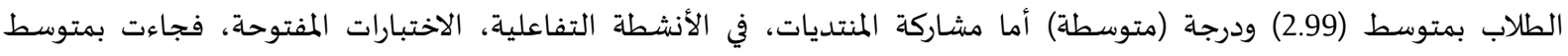

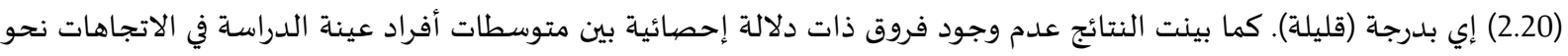

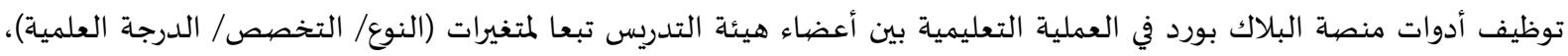

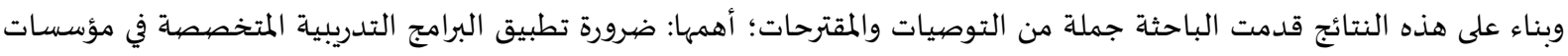

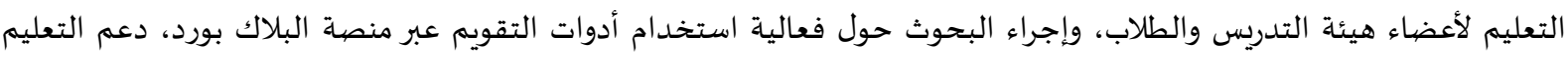

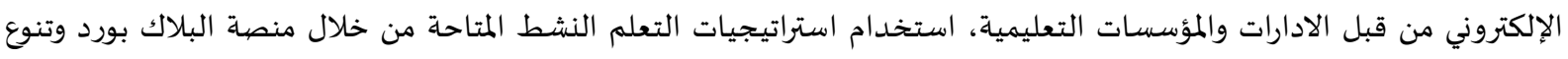

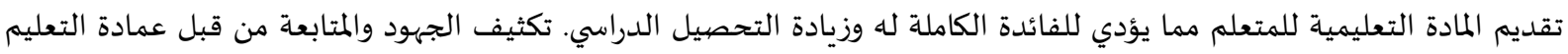
الإلكتروني وتقنية المعلومات بالجامعة لبلوغ الاستفادة الكاملة.

الكلمات المفتاحية: اتجاهات، التعليم الإلكتروني، البلاك بورد، أعضاء هيئة التدريس، جامعة جازان. فيروس كورونا.

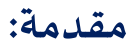

أصبحت أنظمة إدارة التعلم (LMS) وسيلة يعتمد عليها بكثرة في التدريس والتدريب سواء في التعليم

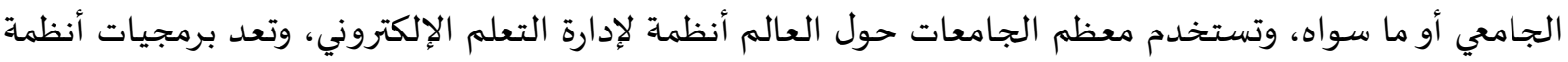

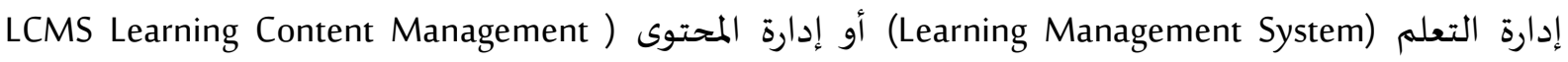

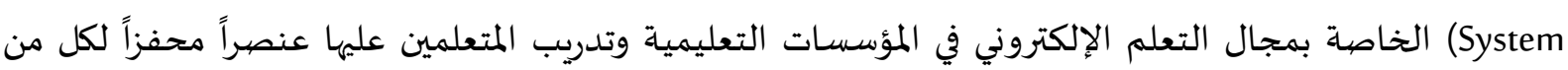

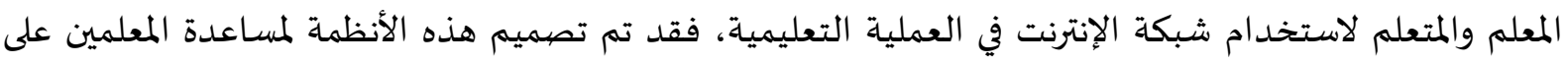

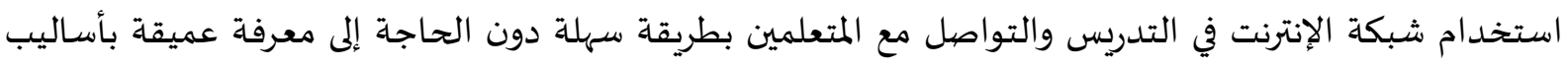

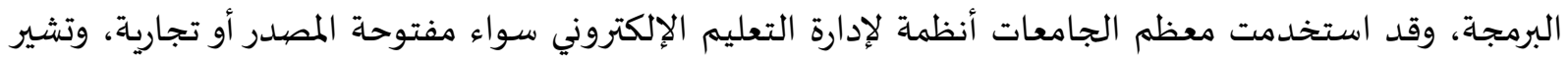
الدراسات إلى أن 90\% من الجامعات الامريكية تقدم برامجها عبر أنظمة إدارة التعليم الإلكتروني (عبدالحميد، الحمبه

مثلما اجتاح وباء كورونا المستجد "كوفيد 19" حواجز الزمان والمكان، جاءت دعوات "التعلم عن بعد" -

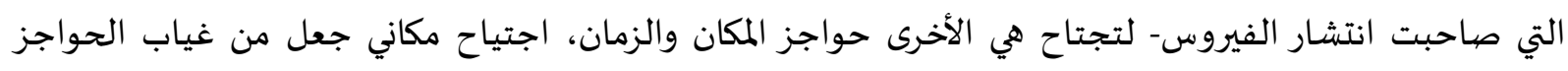

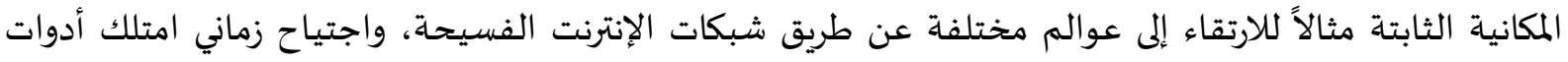

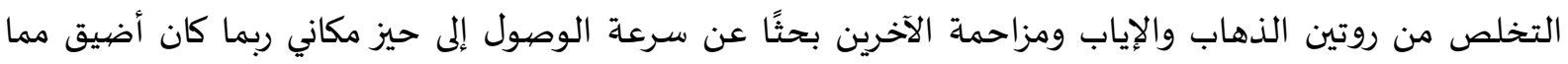

تحتمله رحابة العقول.

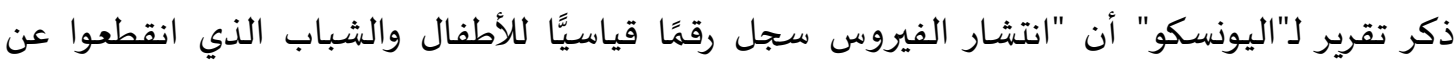

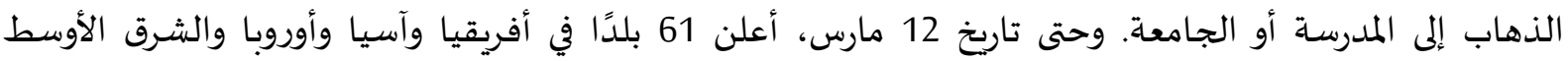

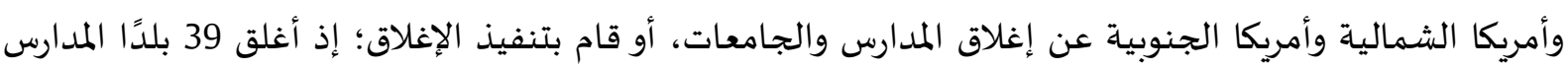

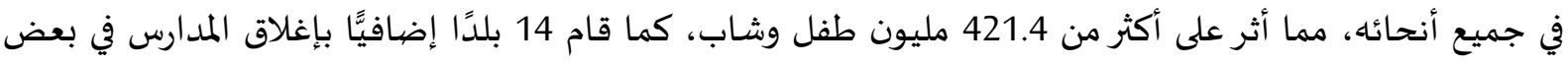

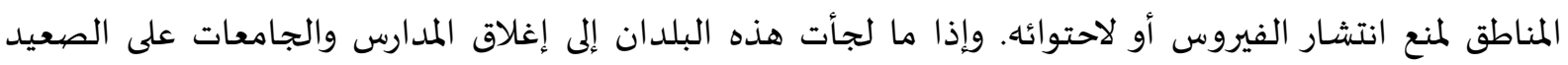

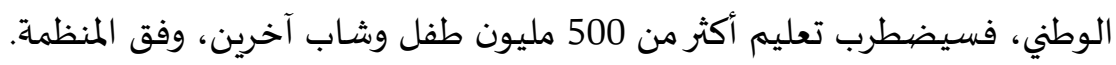

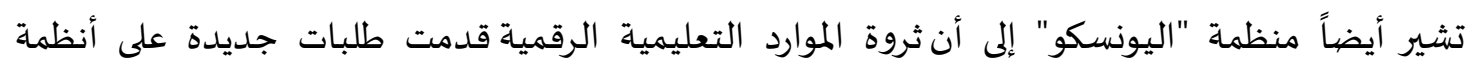
ومؤسسات التعليم العالي، التي تشمل تطوير مناهج ابتكارية وبرامج دراسية ومسارات تعليمية بديلة وطرق التعليم

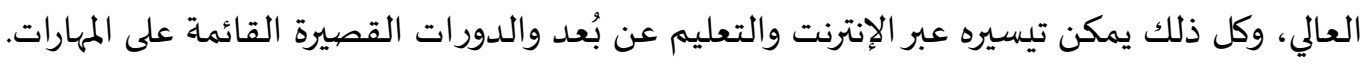


واضيعت المنظمة مجموعة من البرامج التي تساعد على التعلم عن بعد، ومنها تطبيق "بلاك بورد" (Black

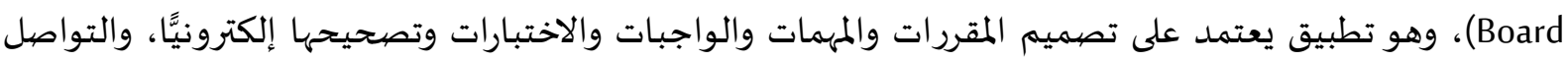
مع الطلاب من خلال بيئة افتراضية وتطبيقات يتم تحميلها عن طريق الهواتف الذكية. (بنك المعرفة المصري،

تعمل وحدة التعليم الإلكتروني وتقنية المعلومات بجامعة جازان لمواكبة التطور في تقنيات التعليم والتعلم

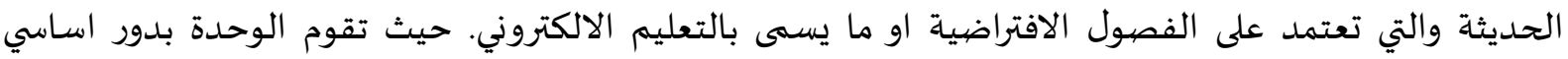

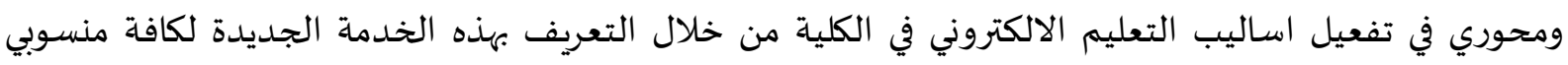

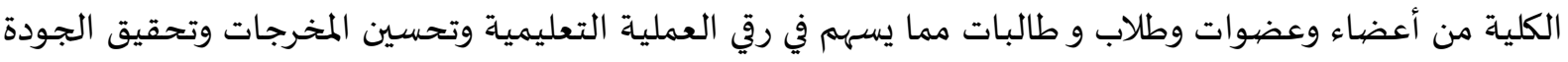

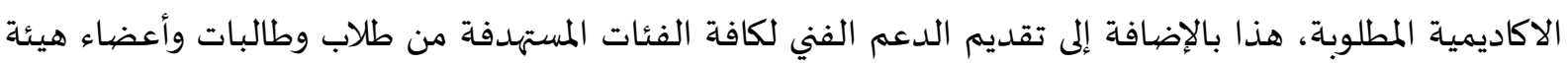

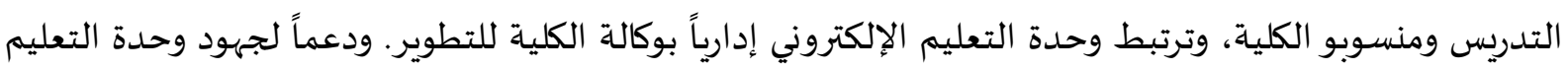
الإلكتروني وتقنية المعلومات بجامعة جازان تقدمت الباحثة بالدراسة الحالية وحتدية.

مشكلة الدراسة: في إطار حرص جامعة جازان على إظهار النجاحات التي حققتها بكلياتها المختلفة والاستفادة من خدمات

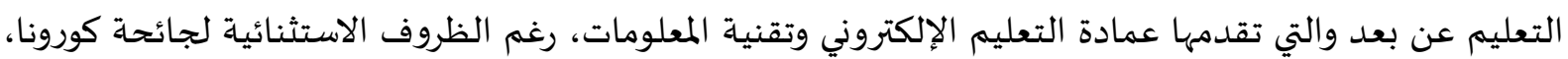

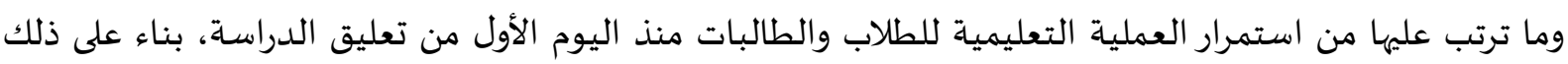

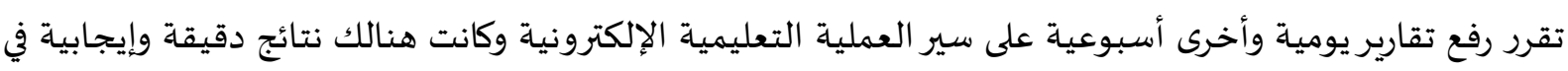

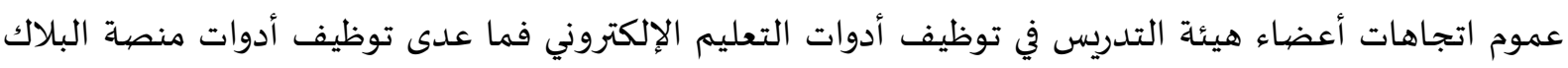

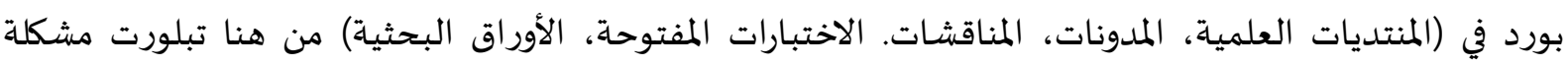

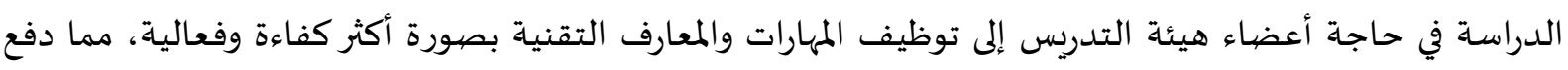
الباحثة لدراسـة هذه الواقعة بحكم أنها عضوه في وحدة التعليم الإلكتروني بكلية التربية.

$$
\text { تساؤلات الدراسـة: }
$$

1- ما اتجاهات أعضياء هيئة التدريس نحو توظيف أدوات التعليم الإلكتروني منصاة البلاك بورد في العملية التعلمية بجامعة جازان؟

2- هل هنالك فروق ذات دلالة إحصائية عند مستوى (0.05>0) بين استجابات أفراد عينة الدراسة من أعضاء

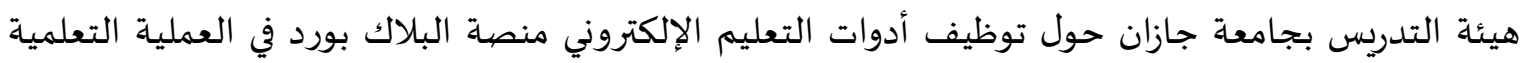

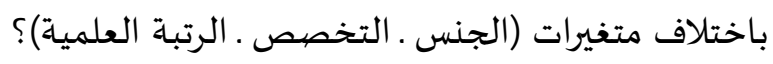

أهداف الدراسة:

تهدف الدراسة إلى:

1. التعرف على اتجاهات أعضاء هيئة التدريس بجامعة جازان نحو توظيف أدوات التعليم الإلكتروني منصية

$$
\text { البلاك بورد في العملية التعلمية. }
$$

2. التعرف على أثر بعض المتغيرات المستقلة (الجنس ـ التخصص ـ الرتبة العلمية) في إحداث فروق ذات دلالة

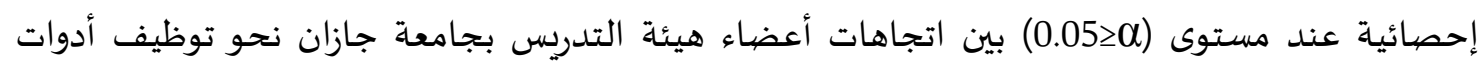

$$
\text { التعليم الإلكتروني منصة البلاك بورد في العملية التعلمية. }
$$


1. حث عمادة التعليم الإلكتروني والتطوير المهني بجامعة جازان لتطبيق البرامج التدربيية المتخصصة لأعضاء هيئة

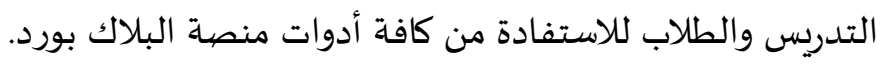

2. ت تدعم التقارير المنجزة من قبل وحدات التعليم الإلكتروني بالكليات واتخاذ القرارات المناسبة.

3. استخدام استراتيجيات التعلم النشط المتاحة من خلال منصة البلاك بورد وتنوع تقديم المادة التعليمية للمتعلم مما يؤدي للفائدة الكاملة له وزيادة التحصيل الدراسي.

4. الدعم والتدريب لأعضاء هيئة التدريس بجامعاة جازان لرفع كفاءة الاداء وجودة المخرج التعليمي.

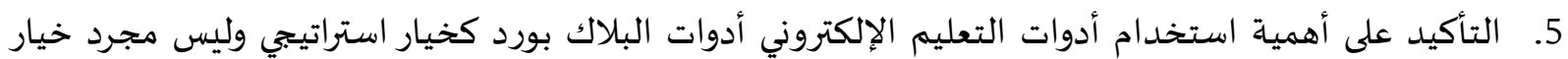

بديل.

6. مواكبة الاتجاهات الحديثة في استخدام منصة البلاك بورد وتفعيلها والاستفادة منها في العملية التعلمية.

حدود الدراسة:

تقتصر هذه الدراسة على الحدود الآتية:

- الحدود الموضوعياة: قياس اتجاهات أعضاء هيئة التدريس بجامعة جازان نحو توظيف أدوات التعليم

الإلكتروني منصية البلاك بورد في العملية التعلمية.

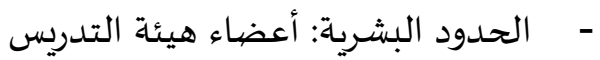

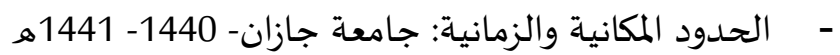

مصطلحات الدراسة:

- التعليم الإلكتروني e- learning: " يعرفه إسماعيل (2009، 393) بأنه " عملية توظيف شيكات المعلومات والبرمجيات التعليمية متعددة المصادر باستخدام وسائل التقييم لتجميع وتحليل استجابات الطلاب بما يساعد الماتد

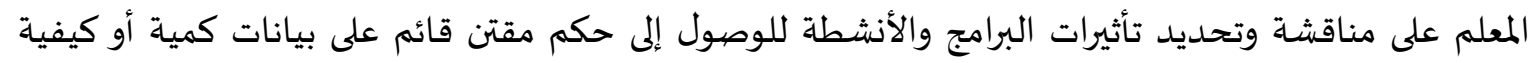

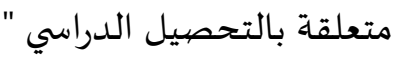

O ميعرف إجرائيا: بأنه: "استخدام الوسائط الإلكترونية المعتمدة على شبكة الإنترنت بشكل متزامن أو غير متزامن

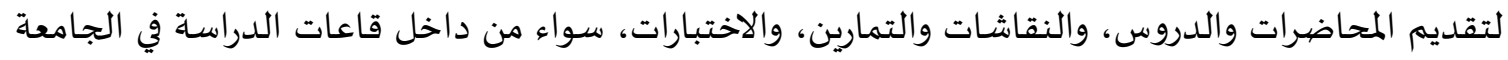
أو خارجها من خلال البوابة الإلكترونية لموقع الجامعة، حيث يكون دعما للطرق التقليدية في قاعات الدراسة واتِ

وليس بديلا عنها".

- مفهوم تقنية البلاك بورد: يعرّفه شو ولي (Chon\&Lin, 2005)على أنه: "نظام تفاعلي متكامل لإدارة عملية

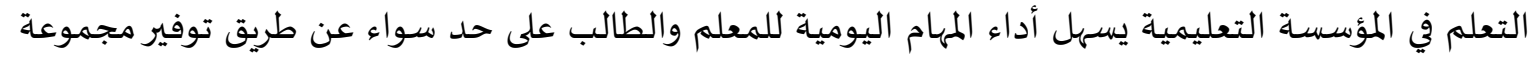

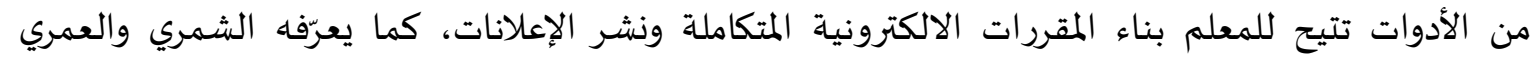

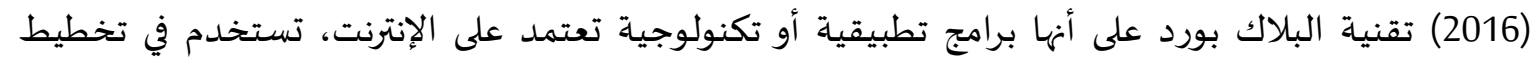

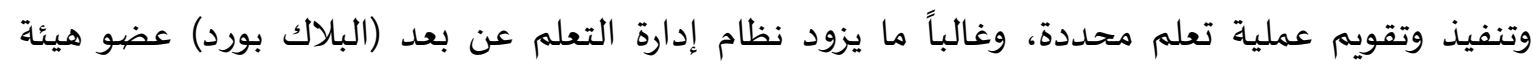
التدريس بطريقة إنشاء وتقديم المحتوى، ومشاركة الطلاب وتقويم أدائهم. 
- الاتجاه: يعرفه نيتكو ( Nitko,2001:450بأنه " شعور ايجابي أو سلبي نحو موضوع أو شخص أو فكر معين "

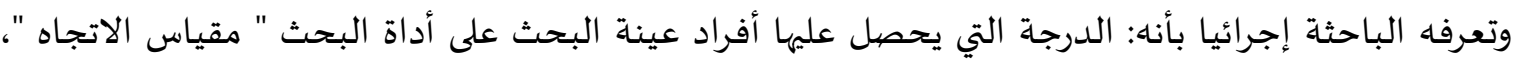

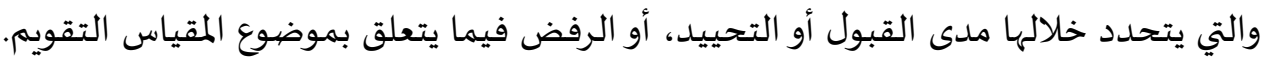

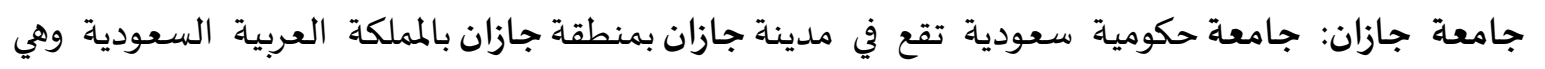

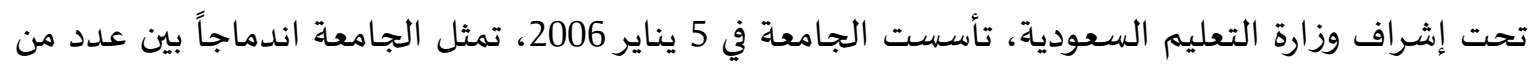

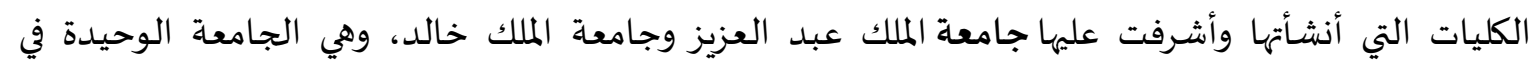
منطقة جازان. (البوابة الإلكترونية لجامعة جازان)

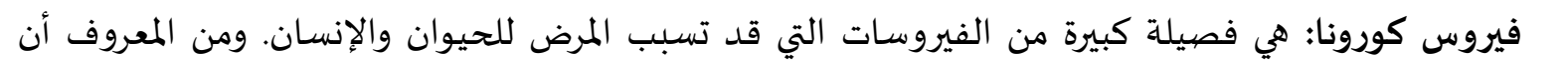

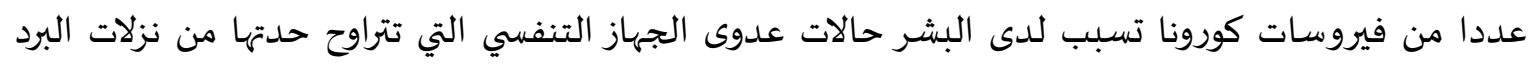

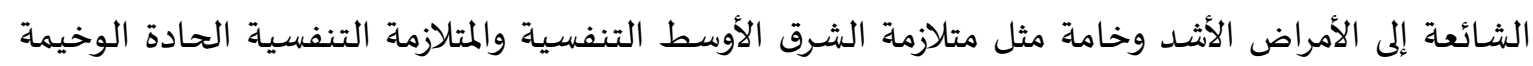
(السارس). ويسبب فيروس كورونا المكتشف مؤخرة مرض فيروس كورونا كوفيد -9 19. (منظمة الصحة الصناف العالمياة،

(2020

2- 2 - الإطار النظري والدراسـات السـابقة أولاً - الإطار النظري: نشأة التعليم الإلكتروني: ظهر الاهتمام بمفاهيم التعليم وقضاياه قبل عقد التسعينيات، ففي عام 1982 م ثارت الحدى الإى الدراسات

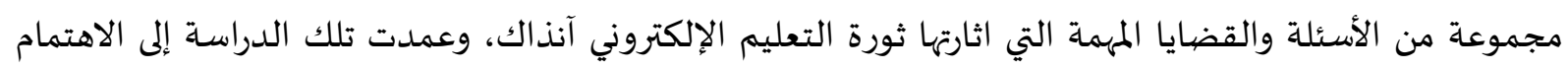

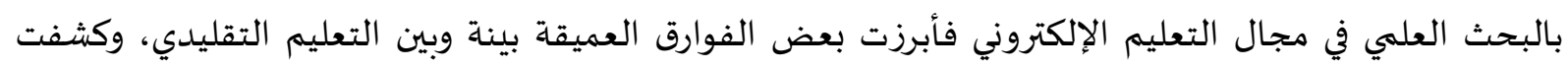

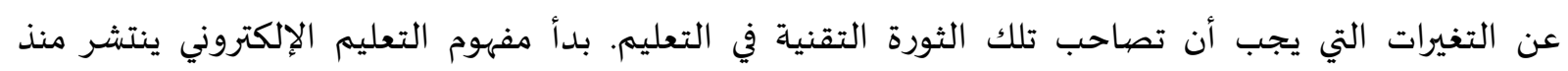

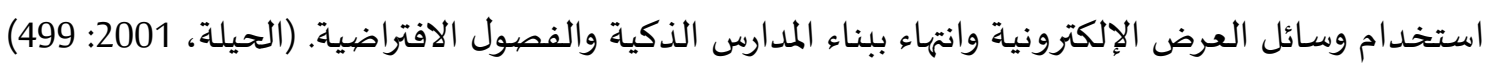

مفهوم البيئات التعليمية الإلكترونية E-Learning Environment:

لقد تعددت مفاهيم البيئات التعلمية الإلكترونية حسب الهيدف الاساسي من استخدامها الهابها ومدى توظيفها لتعليم الطلبة، ومع ذلك لم يكن هنالك اختلاف ملحوظ في جوهرها ومن هذه المفاهيم:

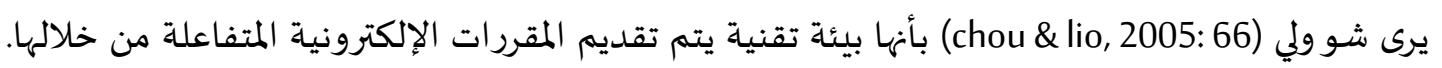

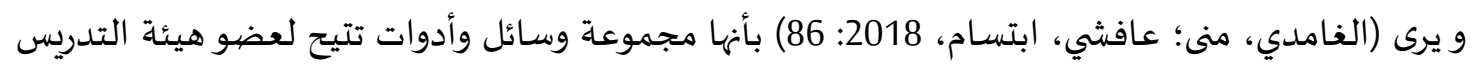

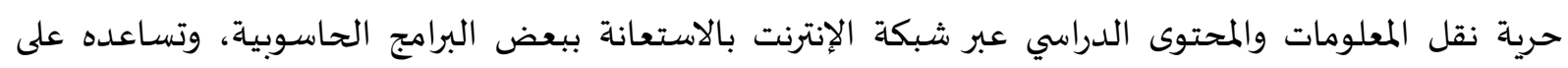

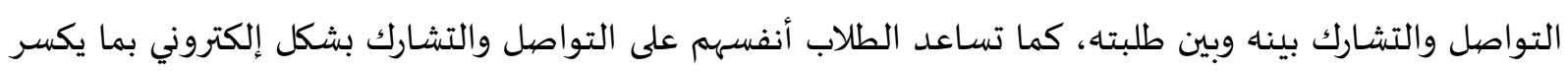
حاجزي الوقت والمكان. و يرى كل من (الشهري وعبيد، 2014: 224) بيئة التعلم الإلكترونية بأنها المنصة أو الحيز الذي يتيح عرض الماض

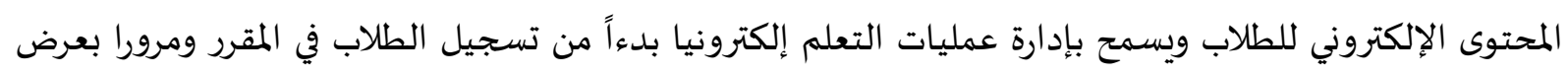
المحتوى والتفاعل معه وتقييم أداء الطالب ومدى تعلمها. 
ولقد اتفقت التعريفات السابقة على أن بيئات التعلم الإلكترونية عبارة عن بيئة تعلم إلكترونية يتعلم من

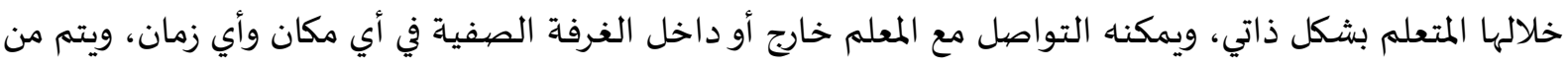
خلال هذه البيئة تقديم الأنشطة المتنوعة حسب قدرات المتعلمين، وتقديم المحتوى التعليمي والتقويم اللازم لأداء

المتعلمين.

أنواع البيئات التعليمية الإلكترونية:

هنالك عدة انوع للبيئات التعلمية الإلكترونية يمكن استخدافيها التئية في التعليم والتعلم: العليم الشبكي المباشر: تقدم فيها المادة التعليمية بشكل مباشر بواسطة الشبكة.

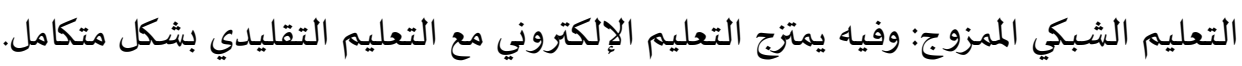
التعليم الشبكي المساند: وفيه يتم استخدام الشبكة من قبل الطلبة للحصول على مصادر المعلومات المختلفة.

البيئات الواقعية: وهي مرتبطة بأماكن محددة وتقدم ضمن مبنى يتوفر فيا تجهيزات مادية، وهي أماكن

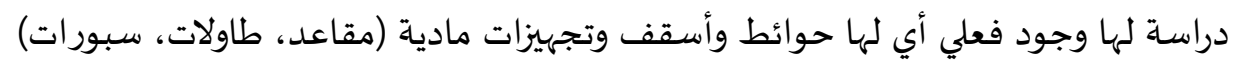
البيئات الافتراضية: وهي بيئات تحاكي الواقع تنتج بواسطة برمجيات (أدوات)الواقع الافتراضي وتوجد على على الى

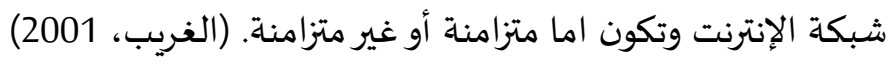

\section{مكونات البيئات التعليمية الإلكترونية:}

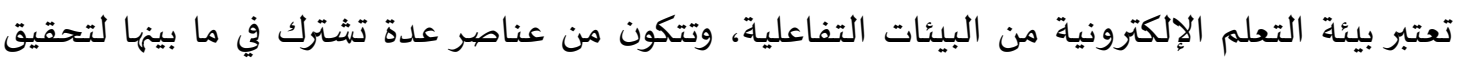
الأهداف التعليمية المرجوة، وتتكون بيئات التعلم الإلكترونية كما وضحها (عقل وآخرون، 2012: 12) مما يلي:

أنظمة التعلم الإلكترونية: تنقسم أنظمة إدارة التعليم الإلكتروني إلى برامج تجارية أو مفتوحة المصديدر (مجانية)، ويتم دفع مبلغ من

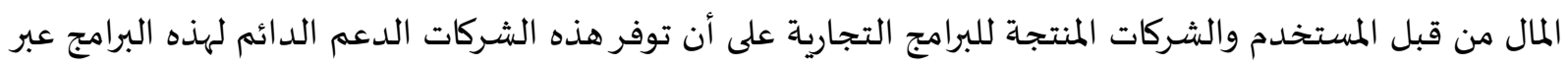

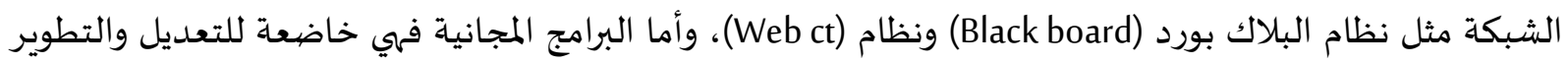

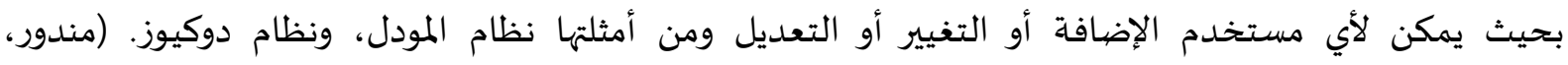

$$
\text { نظتمل أنظمة بيئات التعليم الإلكترونية على: نظم إدارة التعلم. }
$$

توفر نظم إدارة أنشطة التعلم بيئة مناسبة للمتعلمين للتواصل والتفاعل، وغالبا ما تكون نظم إدارة أنشطة التعلم الإلكترونية مفتوحة المصدر لتسهيل عملية تأليف الأنشطة التعليمية حيث توفر العديد من الإمكانات

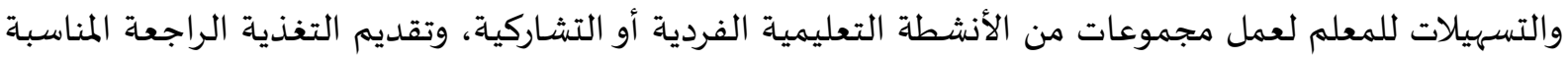
للمتعلمين ويمكن لهذه النظم أن تعمل بصيورة منفصلة أو مدمجة داخل أنظمة أخرى، ومن أمثلة هذه النظم النمانه

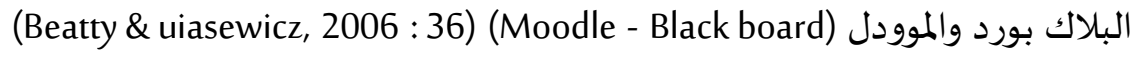


جامعة جازان في ظل جائحة كورونا والتعليم الإلكتروني: أكد معالي مدير جامعة جازان الدكتور مرعي بن حسين القحطاني، تحول الجامعة للتعليم والتعلّم

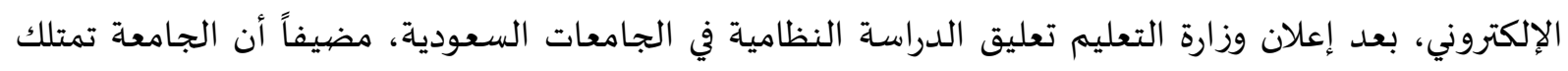

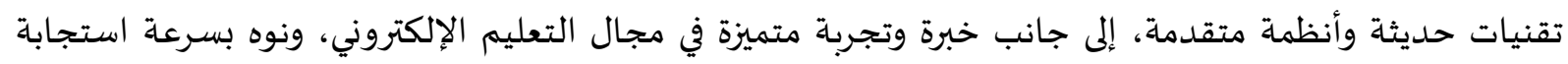

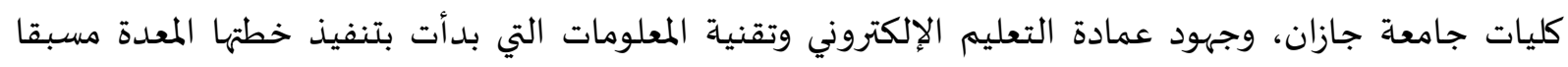

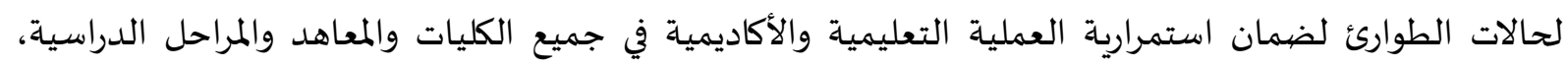
مضيفا أن الجامعة عززت من خطة التحول للتعليم الإلكتروني بعدد من البرامج والقنوات التعليمية المساندة المادية،

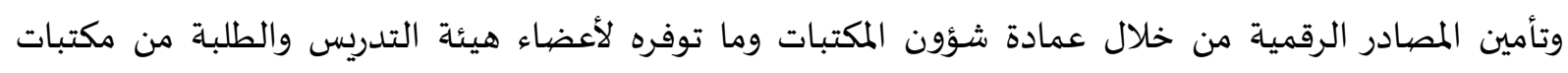

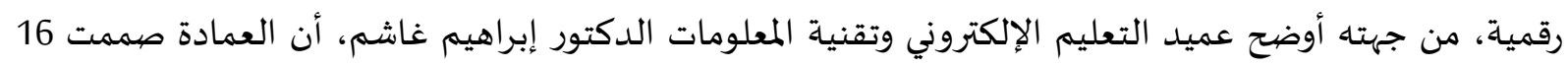

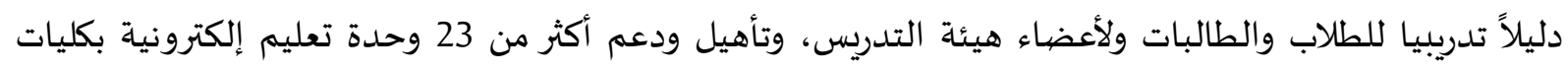

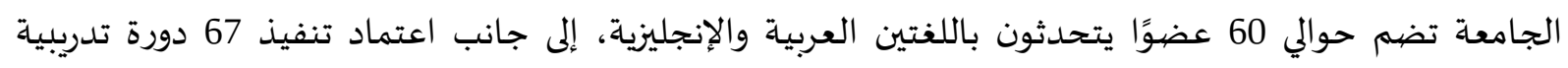

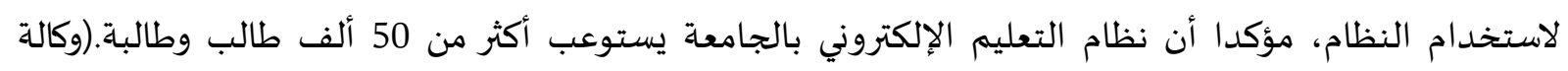
الأنباء السعودية:2020).

ثانياً- منصة البلاك بورد

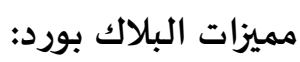

لنظام إدارة التعلم الإلكتروني البلاك بورد العديد من المميزات جعله الأكثر انتشاراً والأكثر استخداماً في التعليم، وهذه المميزات على النحو التالي:

يستطيع الطلاب مشاركة ملفاتهم الشخصية مع الطلاب الآخرون ويمكن تحميل الملفات.

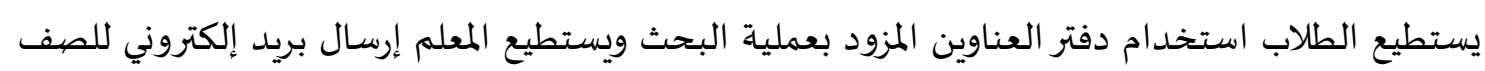
بأكمله باستخدام الاسم المستعار أو العنوان. يستطيع الطلاب إنشاء ملاحظات خاصة حول مقرراتهم.

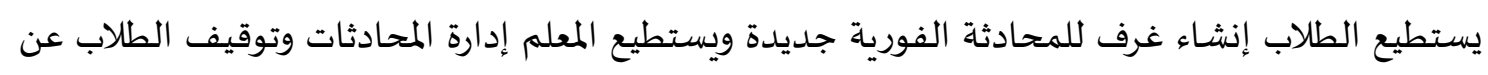

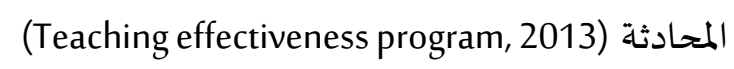
يمكن من خلال البلاك بورد رفع الصهور وملفات البوربوينت كما يدعم البرنامج تطبيقات مشاركة سطح المكتب.

يستطيع المعلم وضع التقديرات ذاتياً للطلاب ووضع وقت محدد للاختبار ويسمح للطالب بتعدد المحاولات واستعراض المحاولات السابقة كما يزود النظام ببيانات تحليل الاختبار.

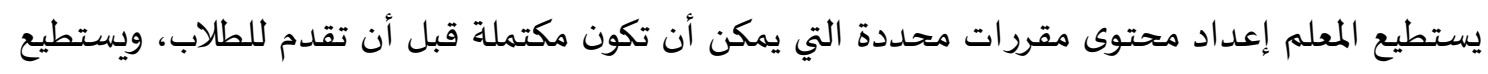

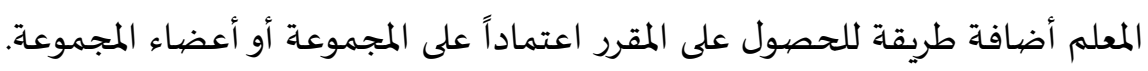

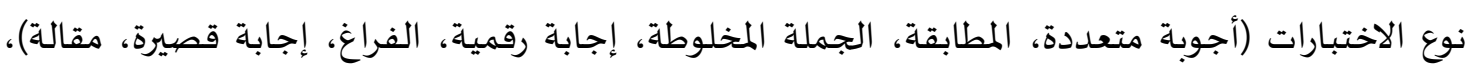

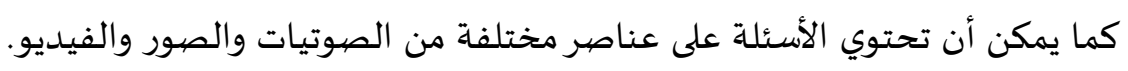

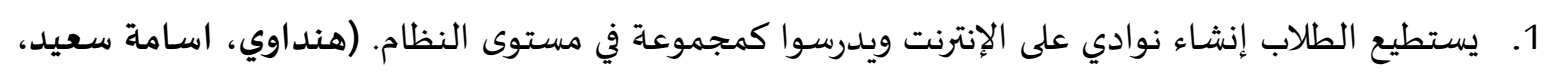

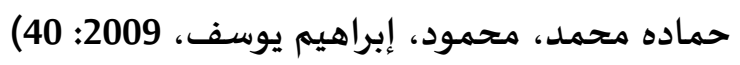


برنامج البلاك بورد ومبادئ التعلم الفعّال: 1. تشجع المتعلم على التواصل والتفاعل مع المعلم ومع زملائه، وذلك استناداً لإرشادات معلمها،، وتعليماته وأنظمة

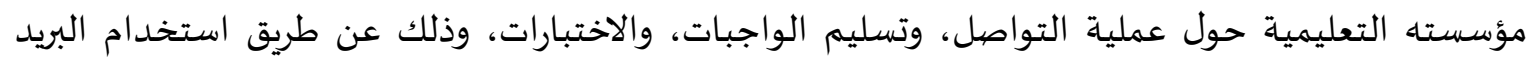
الإلكتروني مما يدعم ويبني روح الفريق ويوجد الثقة لدى الطعابه الثوليه

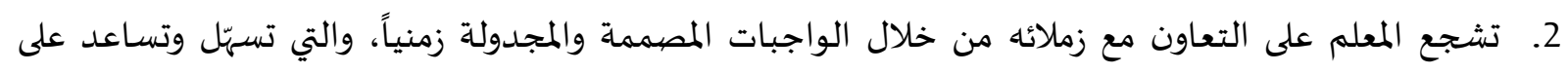

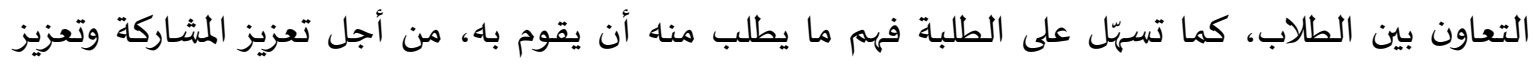
التفاعل الاجتماعي. 3. تشجع التعلم النشط من خلال تقديم مشاريع فردية وجماعية للطلبة عن طريق استخدام نظام الاتصال في

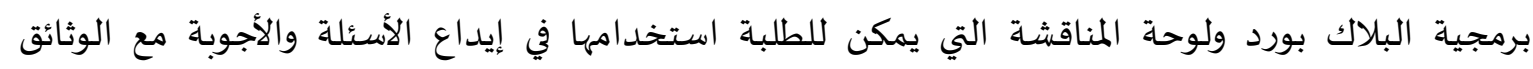

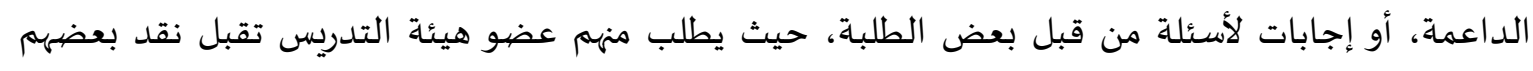

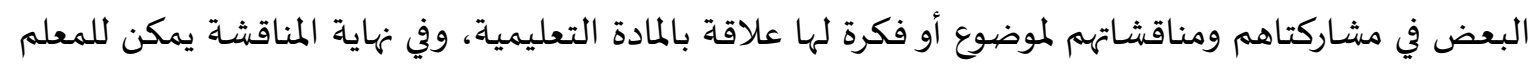

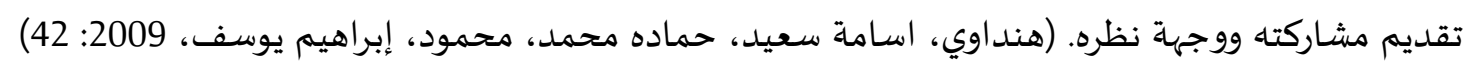

أهمية البلاك بورد في العملية التعليمية: 1. تكمن أهمية النظام في الأدوات والوسائل الكثيرة التي تتيح لأعضاء هيئة التدريس بناء مقررات ديناميكية وتفاعلية بسهولة كبيرة. 2. يساعد المعلم على إدارة محتوى المقرر بطريقة مرنة وبسيطة حتى يتمكن من القيام بالمهام اليومية للعملية التعليمية بشكل فعاّل. 3. يسمح نظام البلاك بورد لأستاذ المقرر ببناء مقررات إلكترونية متكاملة ووضع ملاحظات والأعمال والوظائف

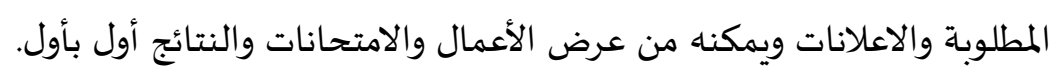

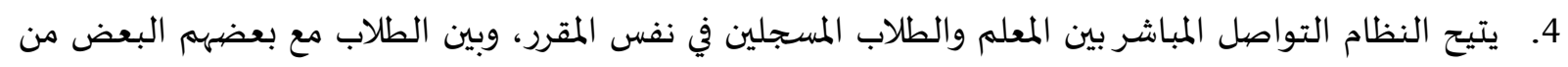
خلال نوافذ الحوار والرسائل الإلكترونية. (هنداوي، اسامة سعيد، حماده محمد، محمود، إبراهيم يوسف،

$$
\text { 1. جبيقات تقنية البلاك بورد في التدريس }
$$

قامت عمادة التعلم الإلكتروني والتعلم عن بعد بجامعة الملك سعود بأبحاث موسعة عن نظم إدارة التعلم

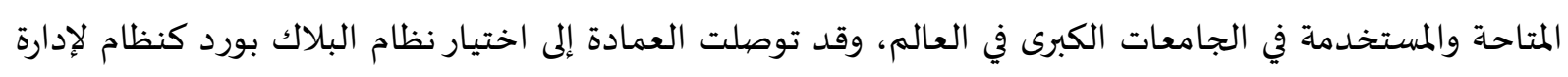

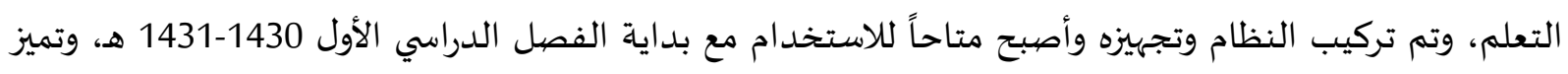
هذا النظام بسهولة الاستخدام مما يسـاعد على انتشاره بين أعضاء هيئة التدريس والطلاب، واحتوائه على الكثير

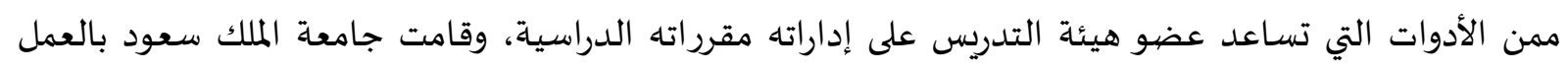

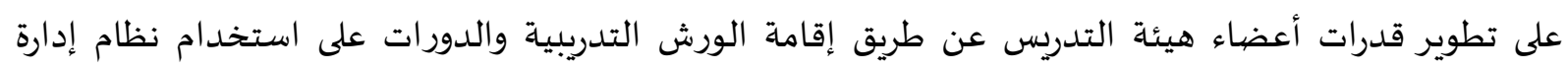
التعلم بلاك بورد وإدارة العلمية التعليمية بكل سهولة ويسر، ولازالت تعمل على ذلك.(هنداوي، واخرون، 2009) 
تمتلك الجامعة بيئة إلكترونية متكاملة، وهي تعد الأولى من نوعها على مستوى الجامعات السعودية، إذ إذ إذإ تعتمد على نظام البلاك بورد أحد أقوى الأنظمة العالمية لإدارة التعلم الإلكتروني والتعلم من بعد، وبها أيضاً أنظمة الاختبارات الإلكترونية، كما تحتوي على أنظمة لتسجيل المحاضرات والمؤتمرات الإلكترونية ونقلها على الإنترنت،

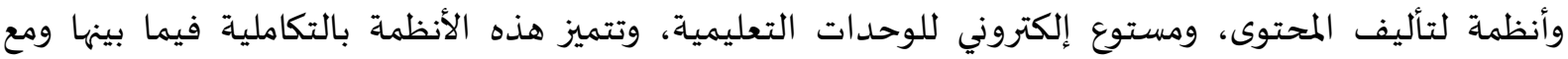

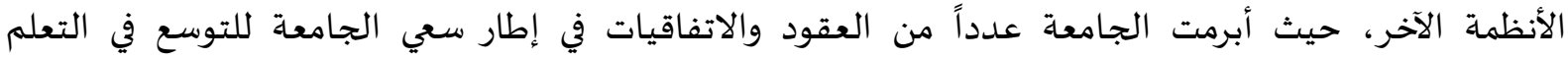

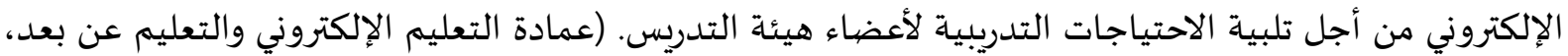

3. جامعة الملك عبد العزيز: تعتمد حالياً الملك عبدالعزيز نظام البلاك بورد كنظام لإدارة العلمية التعليمية لكافة الطلاب والطالبات في جميع البرامج الأكاديمية (انتظام، تعليم عن بعد)، وذلك ليحل بديلاً عن الأنظمة السابقة كنظام سنترا، ونظام إيميس.(عمادة التعليم الإلكتروني والتعليم عن بعد، 2019)

معوقات استخدام تقنية البلاك بورد: صعوبة تطبيق التعلم الإلكتروني لبعض المقررات التي تحتاج إلى مشاهدة واقعية: من الممكن دمج المعامل الافتراضية في نظام البلاك بورد. تُون قلة الخبرة في استخدام نظام إدارة التعلم الإلكتروني، وضعف التخطيط للمحاضرات التزامنية: من الممكن

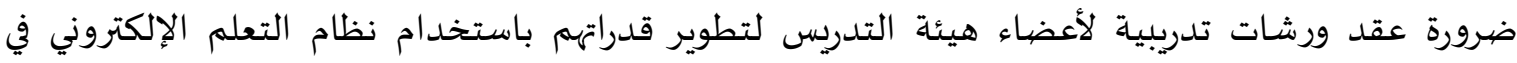
التدريس. عدم امتلاك الطلبة لأجهزة حاسوب وإنترنت: من الممكن حث جميع الطلبة على اقتناء حواسيب واستخدام

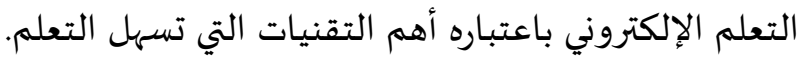
ضعف تأهيل الفنيين وضعف وانقطاع الإنترنت: من الممكن عمل دورات تأهيلية مستمرة للفنيين في تقنيات التعليم. ضعف المحاضرات الإرشادية واللقاء التثقيفية: من الممكن عمل دورات تأهيلية وبروشورات تثقيفية مستمرة.(هنداوي، اسامة سعيد، حماده محمد، محمود، إبراهيم يوسف، 2009: 53)

طرق التغلب على معوقات تقنية البلاك بورد: عدم تقديم دورات تدريبية للطلاب على كيفية استخدام نظام إدارة التعلم الإلكتروني (البلاك بورد) دمجه

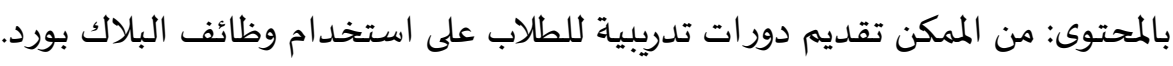
عدم توفر دليل إرشادي للطلاب كيفية استخدام نظام إدارة التعلم الإلكتروني (البلاك بورد): من الممكن إعداد

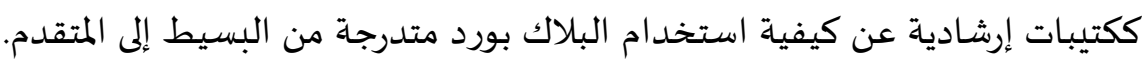
تعتبر تكلفة الإنترنت عالية: من الممكن إعداد معامل لازمة في الكليات وإتاحتها لاستخدام الطلاب في كل وقت. قلة استخدام أعضاء هيئة التدريس نظام إدارة التعلم الإلكتروني (البلاك بورد) في التدريس: من الممكن حث دمثئ أعضاء هيئة التدريس على دمجها في المحتوى، حتى تدعم استخدام الطلاب من خلال تقديم الحوافز المادية المعنوية (هنداوي، اسامة سعيد، حماده محمد، محمود، إبراهيم يوسف، 2009: 53) 
ثانياً- الدراسات السابقة: - - هدفت دراسـة الدسماني والعامر (2017) إلى تجربة جامعة الملك سعود في تطبيق تقنية البلاك بورد من وجهاة

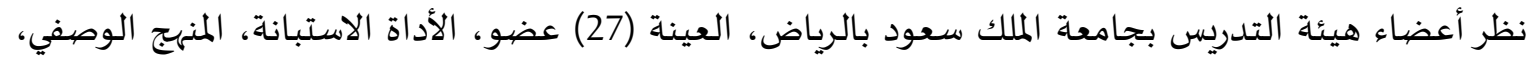
من أبرز النتائج أن أفراد عينة الدراسة موافقون بدرجة كبيرة على ستة من أنماط استخدام أعضاء هيئة النياء

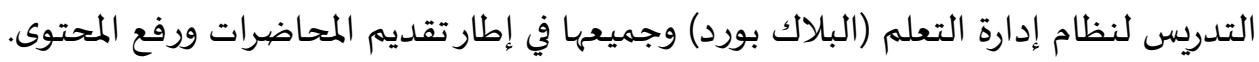

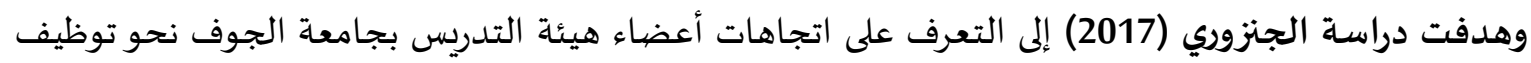
أدوات التقويم الإلكتروني باستخدام نظام البلاك بورد في العملية التعليمية، وتكونت عينة الدراسة من العناء (86)

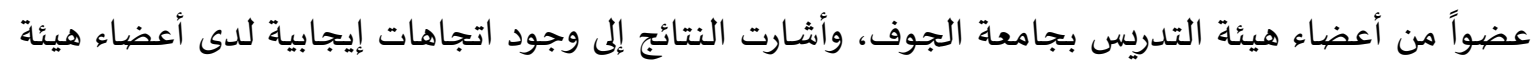

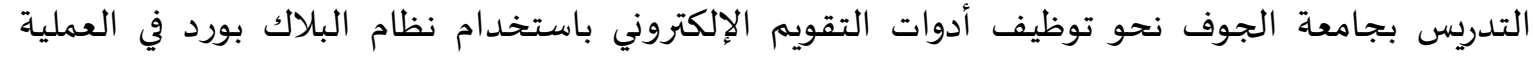

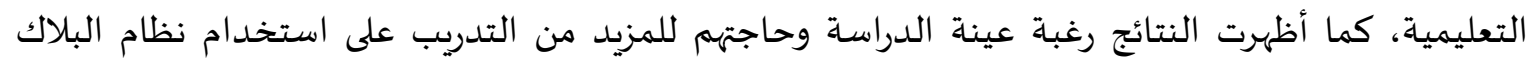

- كما هدفت دراسة الشمري والعمري (2016) إلى التعرف على واقع استخدام أعضاء هيئة التدريس بجامعة اليرموك لنظام البلاك بورد، وتكونت عينة الدراسة من (284) عضواً، وتوصلت في نتائجها إلى أن تقديرات

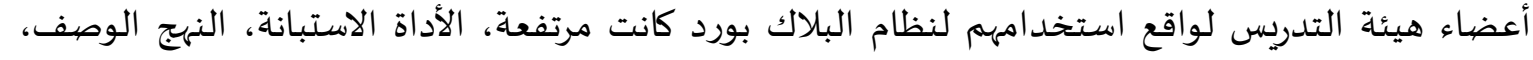

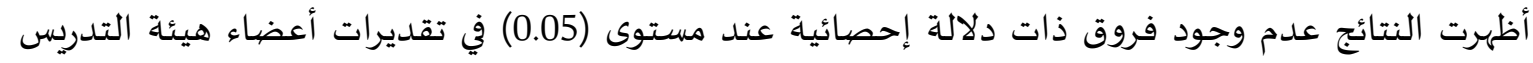
لواقع استخدامهم لنظام البلاك بورد تعزى لكل من متغيري الكلية والرتبة الأكاديمية.

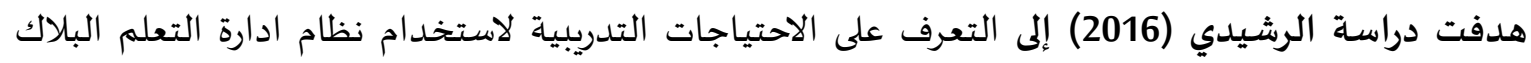

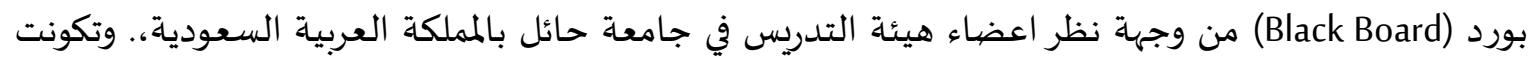

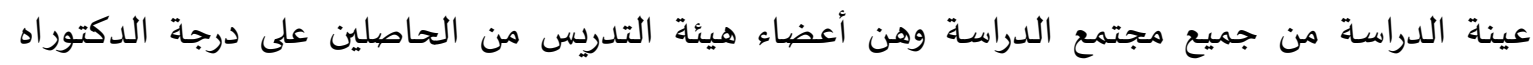

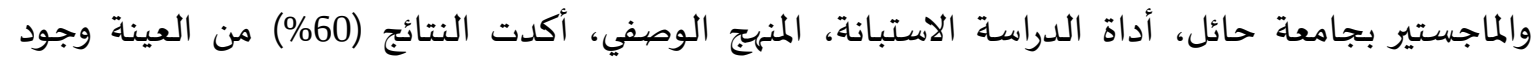
صعوبات في التعامل مع أدوات البلاك بورد ووجود ادهن احتياج للتدريب.

وسعت دراسة البلاصي (2016) إلى التعرف على اتجاهات اعضاء هيئة التدريس بجامعة حائل نحو استخدام

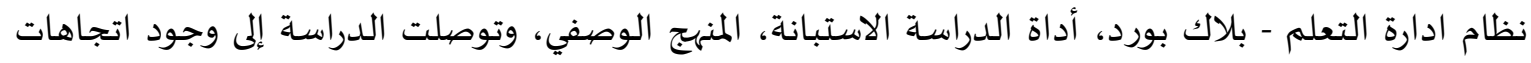

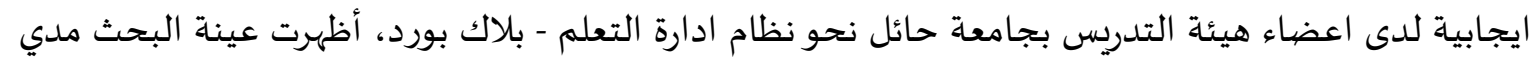

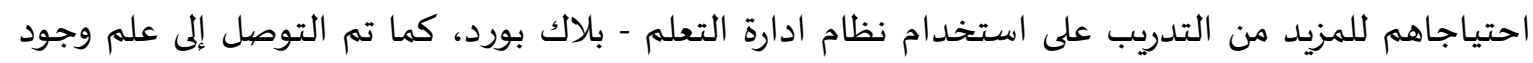

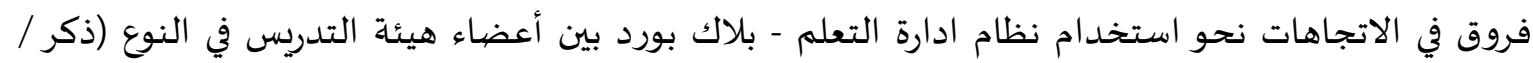
أنثي) وكذلك في طبيعة عملهم في الكليات سواء النظرية أو العملية. وهدفت دراسة السدحان (2015) إلى الكشف عن اتجاهات الطلبة وأعضاء هيئة التدريس في كلية علوم الحاسب والمعلومات بجامعة الإمام محمد بن سعود نحو استخدام نظام إدارة التعلم الإلكتروني بلاك بوراء (Blackboard)

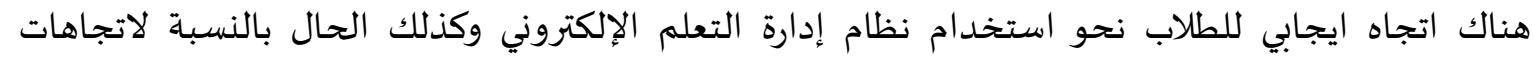
أعضاء هيئة التدريس جاءت ايجابية. هدفت دراسة الشهري ومحمد (2014) هدفت إلى قياس فاعلية التدريب على استخدام برنامج البلاك بورد

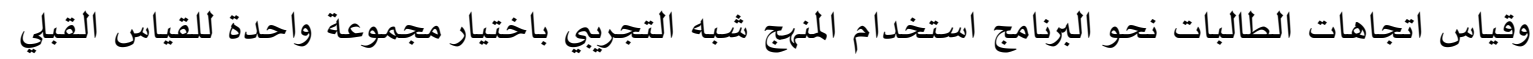
والبعدي وعددها (40) طالبة من طالبات المستوى السادس بكلية التربية جامعاة نجران، واستخدمت الدراسية 
الاستبيان، وأشارت النتائج إلى أن تدريب الطالبات على نظام إدارة التعلم الالكتروني البلاك بورد قد أضفى

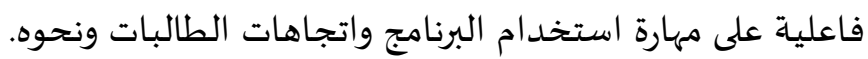
في حين هدفت دراسة الجراح (2011) إلى معرفة اتجاهات طلبة الجامعة الأردنية الملتحقين في برنامج الدبلوم

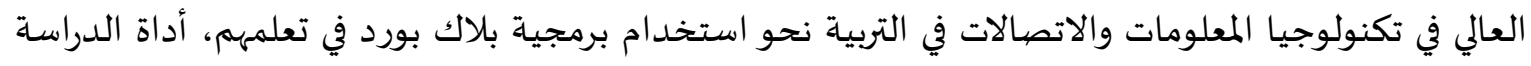

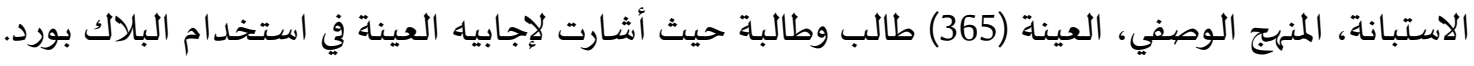

\section{التعليق على الدراسات السابقة:}

تلاحظ الباحثة من الدراسات ما عمل على قياس اتجاهات أعضاء هيئة التدريس فقط (الدسماني والعامر

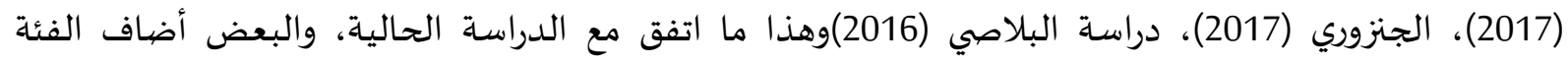

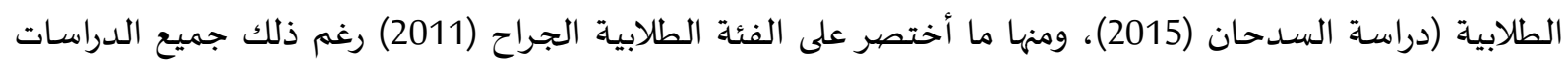
أكدت على:

الاتجاهات الإنجابية لأعضاء هيئة التدريس وللطلاب نحو استخدام التعليم الالكتروني منصية البلاك بورد في العملية التعليمياة.

لا توجد فروق بين اعضاء هيئة التدريس ذات دلاله إحصائية عند (0.05)تعزى (للجنس. الرتبة التخصص) ضرورة التدريب والتأهيل للأعضاء والطلاب حتى تكتمل الفائدة من استخدام أدوات التعليم الإلكتروني، وهذا ما أكدت عليه الدراسة الحالية

3- منهجية الدراسـة وإجراءاتها: أولاًَ منهج الدراسـة:

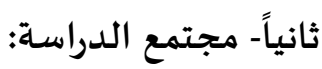
يتمثل مجتمع الدراسة في أعضاء هيئة التدريس بـ (كلية التربية، الكلية الجامعية بصبيا، كلية الآداب والعلوم الإنسانية، كلية العلوم) والبالغ عددهم (1440 عضو وعضوة تقريبا) تم اختيارها قصديا من (26 كلية) ولصعوبة تعميم الدراسة اكفت الباحثة بهذه المجموعة، علماً بأن المجتمع الكلي يبلغ (3000) عضو وعضوة وعضوة.

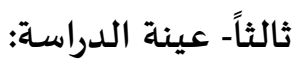
تكونت عينة الدراسة من (90) عضيواً من أعضاء هيئة التدريس بجامعة جازان، وهي تعادل (16\%) من مجتمع الدراسـة. جدول رقم (1) توزيع عينة الدراسة وفق الجنس والرتبة العلمية والتخصص التص

\begin{tabular}{|c|c|c|c|c|c|c|}
\hline \multicolumn{2}{|c|}{ التخصص } & \multicolumn{3}{|c|}{ الرتبة العلمية } & \multicolumn{2}{|c|}{ الجنس } \\
\hline إنساني & علمي & محاضر & أستاذ مساعد & أستاذ مشـارك & أنثى & ذكر \\
\hline 46 & 44 & 30 & 55 & 5 & 60 & 30 \\
\hline $51 \%$ & $49 \%$ & $33.3 \%$ & $61.1 \%$ & $5.6 \%$ & $66.7 \%$ & $33.3 \%$ \\
\hline
\end{tabular}


المجلة العربية للعلوم ونثر الأبحاث ـ مجلة العلوم التريوية و النفسية ـ المجلد الرابع ـ العدد السابع والثلاثون ـ أكتوبر 2020م

\begin{tabular}{|c|c|c|}
\hline التخصص & الرتبة العلمية & الجنس \\
\hline 90 & 90 & 90 \\
\hline $100 \%$ & $100 \%$ & $100 \%$ \\
\hline الإجمالي & الإجمالي & الإجمالي \\
\hline
\end{tabular}

نلاحظ من الجدول أن \%6.7\% من الإناث و 61.1\% أستاذ مساعد بينما 33.33 ذكور 33.3\% محاضرين

بينما تقل نسبة الأستاذ المشارك (5.6\%).

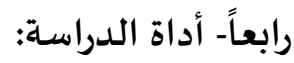

لتحقيق هدف الدراسة قامت الباحثة بإعداد أداة الدراسـة على شكل استبانة، وقد تم تصيميم أداة

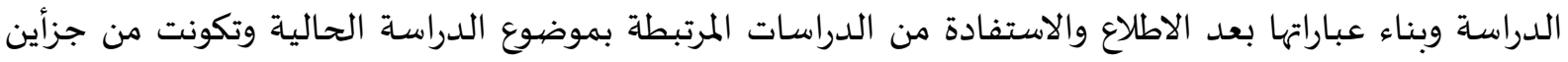

هما:

الجزء الأول: تكون من البيانات الديمغرافية للعينة؛ الجنس والرتبة العلمية والتخصص.

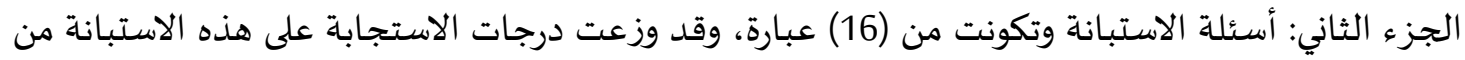

(1- 5) وفق تدرج ليكرت (موافق بشدة، موافق، محايد، غير موافق، غير موافق بشدة).

صددق أداة الدراسة (الاستبانة):

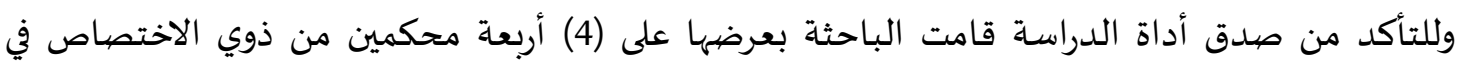

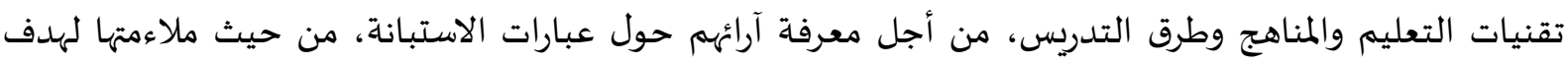

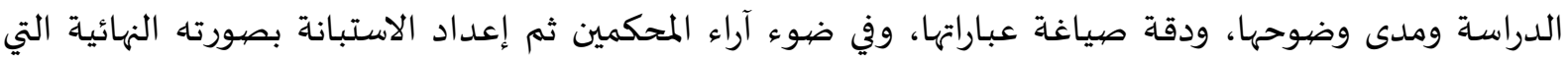

$$
\text { بلغت (16) عبارة. }
$$

ثبات أداة الدراسـة (الاستبانة):

تم تقدير ثبات الاستبانة على أفراد العينة وذلك باستخدام طريقة معامل الثبات ألفا كرونباخ حيث تم

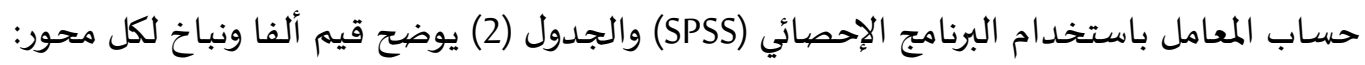

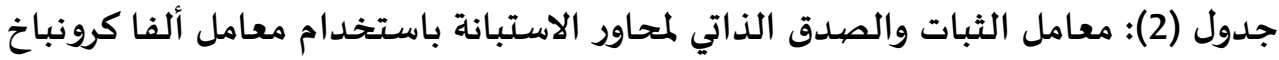

\begin{tabular}{|c|c|}
\hline معامل الصيدق & معامل الثبات \\
\hline
\end{tabular}

.960

.950

توظيف ادوات منصة البلاك بورد في التعليم الالكتروني المتزامن

.961

.951

إعداد الطالب الجامعي علميا وفكريا وابداعيا ونقديا

.961

.951

مشاركة المحتويات وتقديم التعليم الإلكتروني غير متزامن عبر نظام البلاك

.962

.952

بورد

.961

.951

البلاك بورد منصة آمنة وفعالة في تقييم أعمال الطلاب

يتضح من الجدول (2) قد بلغ معامل الثبات لإجمالي محاور الاستبانة (951.) مما يدل على أن درجة الثبات

عالية لمحاور الاستبانة، وأنعكس ذلك على الصدق حيث بلغ (961.) وينطبق ذلك على المجالات الفرعية. 
الوزن النسبي والمعالجات الإحصائية: وزعت درجات الاستجابة على هذه الاستبانة من (1- 5) وفق تدرج ليكرت (موافق بشـدة، موافق، محايد، غير موافق، غير موافق بشـدة). وتم تحديد الموافقة من خلال حسـاب المدى بين الدرجات.

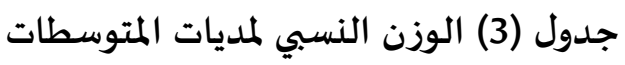

\begin{tabular}{|c|c|}
\hline درجة الموافقة & الوزن النسبي \\
\hline قليلة جداً & 1.80 \\
\hline قليلة & $2.60-1.81$ \\
\hline متوسط & $3.40-2.61$ \\
\hline كبيرة & $4.20-3.41$ \\
\hline كبيرة جدا & $5-4.21$ \\
\hline
\end{tabular}

4- نتائج الدراسـة ومناقشتها أظهر التحليل الإحصائي للبيانات النتائج التالية حسب أسئلة الدراسـة: السؤال الأول: ما اتجاهات أعضاء هيئة التدريس نحو توظيف أدوات التعليم الإلكتروني منصية البلاك بورد في العملية التعليمية بجامعة جازان؟ وللإجابة على هذا السؤال تم حساب المتوسطات الحسابية والانحراف المعياري لاستجابات أفراد الماندان العينة على

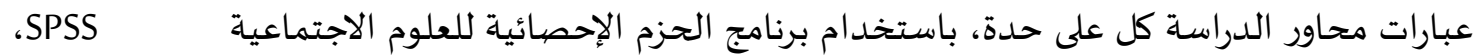

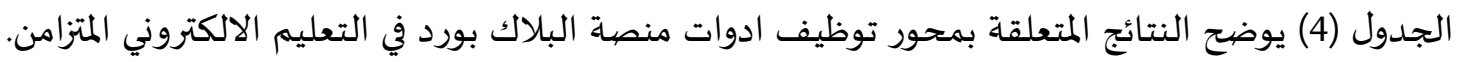
جدول (4): المتوسطات الحسابية والانحرافات المعيارية ودرجة موافقة استجابات عينة الدراسة المرتبطة بمحور توظيف ادوات منصة البلاك بورد في التعليم الالكتروني المتزامن مرتبة تنازليا حسب المتوسطات

\begin{tabular}{|c|c|c|c|c|c|}
\hline التقلفير & 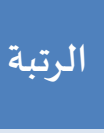 & 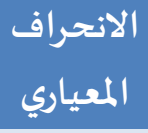 & الحتوسط المسابي & الفة الفـــــــــــــرات & r \\
\hline 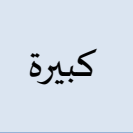 & 1 & .976 & 4.15 & توفر منصـة البلاك بورد المناقشـة والحوار من خلال جلسات & 1 \\
\hline 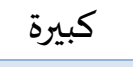 & 2 & 1.12 & 4.11 & يتيح لك اشراك الطالب في المحاضرة & 4 \\
\hline 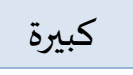 & 3 & 1.02 & 4.10 & تستطيع القاء محاضراتك من أي مكان & 2 \\
\hline 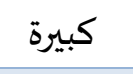 & 4 & .976 & 4.04 & تستطيع تحديد موعد المحاضرة ونهايتها وتاريخها & 3 \\
\hline كبيرة & & .966 & 4.15 & المتوسط الكلي & \\
\hline
\end{tabular}

يتضح من الجدول (4) أن الدرجة الكلية لتوظيف ادوات منصة البلاك بورد في التعليم الالكتروني المتزامن جاءت بمتوسط حسابي (4.15) وانحراف معياري (966.)، وهذا يدل على إيجابية اتجاهات أعضاء هيئة

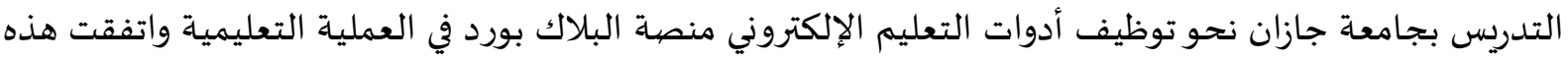
النتائج مع دراسة الدسماني والعامر (2017)، الجنزوري (2017)، البلاصي (2016) السداندان السان (2015). 
جدول (5) المتوسطات الحسابية والانحرافات المعيارية ودرجة موافقة استجابات عينة الدراسـة المرتبطة بمحور

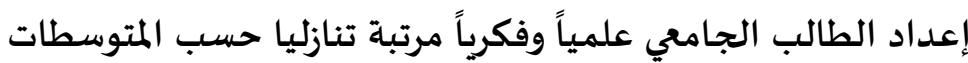

\begin{tabular}{|c|c|c|c|c|c|}
\hline اللفظي & 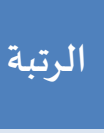 & الانحراف & المستوسط الحسي & الفةـــــــــــــــات & $\hat{\imath}$ \\
\hline 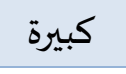 & 1 & .845 & 3.95 & يُمكِنك من اكتشاف مواهب الطالب ودعمها & 2 \\
\hline كبيرة & 2 & .919 & 3.85 & يَمكُنك من تقديم تغذية راجعة لآراء وافكار الطلاب & 3 \\
\hline كبيرة & 3 & .992 & 3.65 & يمكن الطالب من ابداء الراي في المواضيع العلمية والنظرية & 4 \\
\hline متوسط & 4 & 1.05 & 3.23 & تستطيع طرح موضوعات علمياه تدعم الطالب فكريا وإبداعا & 1 \\
\hline كبيرة & & .940 & 3.88 & المتوسط الكلي & \\
\hline
\end{tabular}

يتضح من الجدول (5) أن الدرجة الكلية لمحور إعداد الطالب الجامعي علمياً وفكريا جاءت بمتوسط حسابي (3.88) وانحراف معياري (940،) وهذا يدل على أن جميع العبارات تشكل اتجاهات إيجابية أعضاء هيئة التدريس بجامعة جازان نحو توظيف أدوات التعليم الإلكتروني منصية البلاك بورد في العملية التعليمية، واتفقت هذه النتائج مع دراسة الشهري ومحمد (2014) السدحان (2015)، الجراح (2011). جدول (6) المتوسطات الحسابية والانحرافات المعيارية ودرجة موافقة استجابات عينة الدراسة المرتبطة بمحور

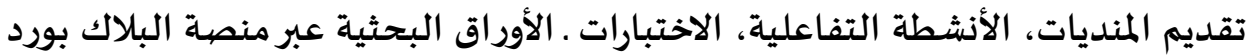

\begin{tabular}{|c|c|c|c|c|c|}
\hline 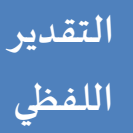 & 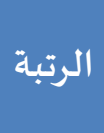 & 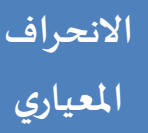 & المتوسط الحسبي & الفةــــــــــــات & $\hat{\imath}$ \\
\hline قليلة & 1 & .846 & 2.59 & توفر لك منصية البلاك بورد مشـاركة الأوراق البحثية & 3 \\
\hline 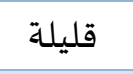 & 2 & 1.037 & 2.35 & يَمكُنك من مشاركة الشـاشـة وعرض نوافذ التطبيق & 1 \\
\hline 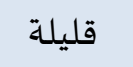 & 3 & 1.002 & 2.55 & تستطيع تسجيل المحاضرة واتاحتها للطالب في أي زمان & 4 \\
\hline 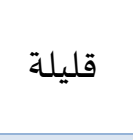 & 4 & .845 & 2.23 & 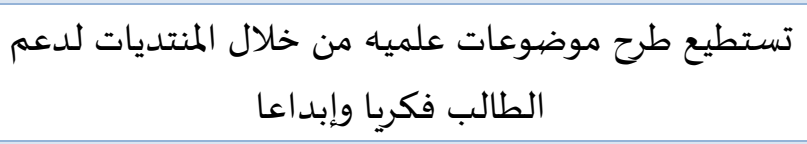 & 2 \\
\hline 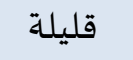 & & .950 & 2.20 & المتوسط الكلي & \\
\hline
\end{tabular}

يتضح من الجدول (6) أن الدرجة الكلية لمحور تقديم المنتديات، الأنشطة التفاعلية، الاختبارات ـ الأوراق

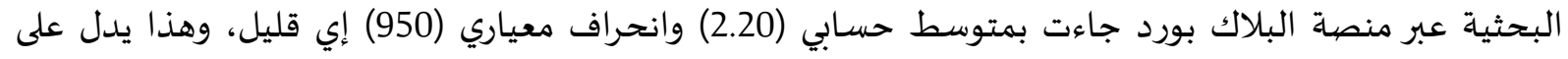
عدم إقبال أعضاء هيئة التدريس على تفعيل تلك الميزات لمنصة البلاك بورد، وتعزي الباحثة ذلك لحداثة الأعضاء بتوظيف أدوات التعليم الإلكتروني وضرورة للتدريب واتفقت هذه النتائج مع دراسة الدسماني والعامر (2017)، الجنزوري (2017) الرشيدي (2016) البلاصي (2016) الشهري ومحمد (2014). جدول (7) المتوسطات الحسابية والانحرافات المعيارية ودرجة موافقة استجابات عينة الدراسة المرتبطة بمحور البلاك بور منصية امنة وسهلة للتقييم مرتبة تنازليا حسب المتوسطات

\begin{tabular}{|c|c|c|c|c|c|}
\hline اللفظير & 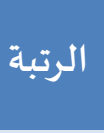 & الانحراف المعياري & الحستوسطي & الفة الـــــــــــــرات & r \\
\hline متوسط & 1 & .977 & 3.02 & يَمكن الطالب من مشاركة أعماله و تقديمها & 2 \\
\hline متوسط & 2 & .932 & 2.60 & يَسهل لك متابعة الانشطة والواجبات وتقديم التغذية المرتدة & 1 \\
\hline
\end{tabular}




\begin{tabular}{|c|c|c|c|c|c|}
\hline التفلير & 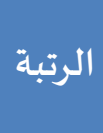 & 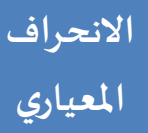 & المتوسط الحسابي & الفةـــــــــــــرات & م \\
\hline & & & & للطالب & \\
\hline متوسط & 3 & .993 & 2.44 & يَتيح لك امكانية اجراء الاختبارات وتصحيحها اليا & 3 \\
\hline قليل & 4 & 1.07 & 2.25 & يَمِكِك من إعداد الاختبارات الكترونيا بطرق مختلفة بحيث & 4 \\
\hline متوسط & & .975 & 2.99 & المتوسط الكلي & \\
\hline
\end{tabular}

يتضح من الجدول (7) أن قيمة متوسط الدرجة الكلية (2.99) وانحراف معياري (975.)لمحور:(البلاك بور منصة آمنة وفعالة في تقييم أعمال الطلاب)، وتعزي الباحثة ذلك لحداثة استخدام المنصة في الاختبارات من قبل اعضاء هيئة التدريس والطلاب، واتفقت هذه النتائج مع دراسة الشهري ومحممد (2014)، الدسماني والعامر (2017). • السؤال الثاني: هل توجد فروق ذات دلالة إحصائية عند (0.05) بين استجابات أفراد عينة الدراسة من فئن

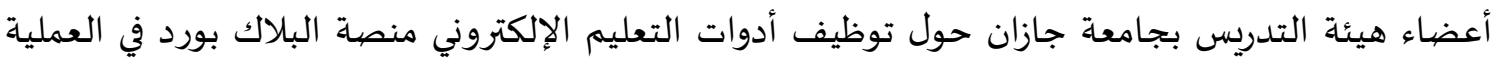
التعليمية باختلاف (الجنس، التخصص، الرتبة العلمية). أولا: التعرف على إذا ما كانت هناك فروق ذات دلاله إحصائية عند (0.05) بين استجابات أفراد عينة

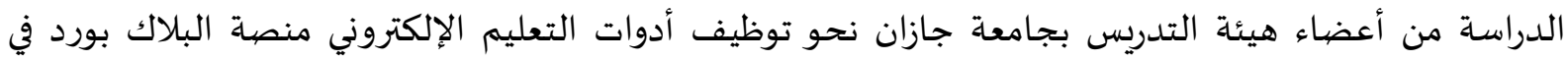

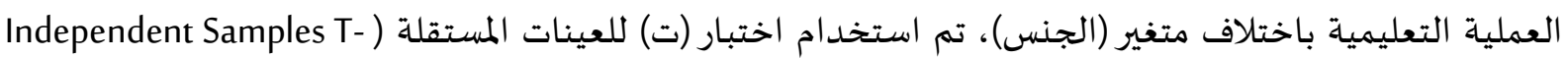

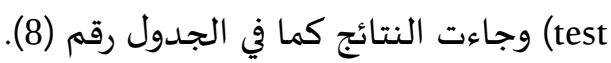
جدول (8) نتائج اختبار (تي تست) لفحص أثر متغير الجنس في اتجاهات أعضياء هيئة بجامعة جازان أنحول

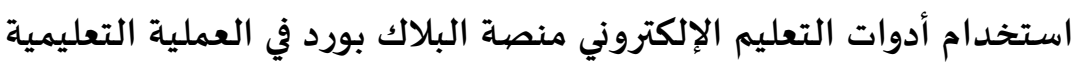

\begin{tabular}{|c|c|c|c|c|c|c|}
\hline مستوى الدلالة & الدلالة & قيمة ت & الانحراف & المتوسط الحسابي & العدد & الفئة \\
\hline غير دالة عند & \multirow{2}{*}{.589} & \multirow{2}{*}{0.355} & 1.17 & 3.26 & 30 & ذكر \\
\hline 0.05 & & & .850 & 4.37 & 60 & انثى \\
\hline
\end{tabular}

نلاحظ من الجدول (8) لا توجد فروق ذات دلالة إحصائية بين متوسطات أفراد عينة الدراسة لمحاور

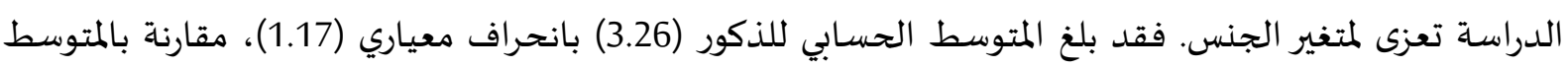

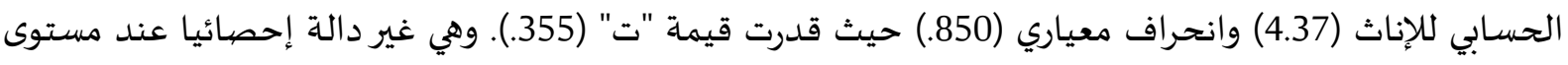
الدلالة (0.05).

ثانياً: التعرف على إذا ما كانت هناك فروق ذات دلاله إحصائية عند (0.05) بين استجابات أفراد عينة

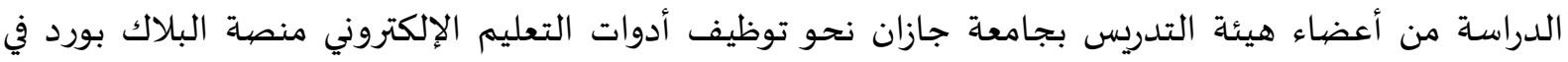
العملية التعليمية باختلاف متغير (التخصص)، تم استخدام اختبار (ت) للعينات المستقلة (Independent Samples (T- test 
جدول (9) المتوسطات والانحرافات المعيارية وقيمة (ت)لاستجابات أفراد عينة الدراسة باختلاف متغير (التخصص (ان)

\begin{tabular}{|c|c|c|c|c|c|c|}
\hline مستوى الدلالة & الدلالة & قيمة ت & الانحراف المعياري & المتوسط الحسبي & العدد & الفئة \\
\hline غير دالة & \multirow{2}{*}{.580} & \multirow{2}{*}{0.450} & 1.18 & 3.28 & 27 & علمي \\
\hline عند 0.05 & & & .890 & 4.36 & 63 & إنساني \\
\hline
\end{tabular}

نلاحظ من الجدول (9) لا توجد فروق ذات دلالة إحصائية بين متوسطات أفراد عينة الدراسة لمحاور

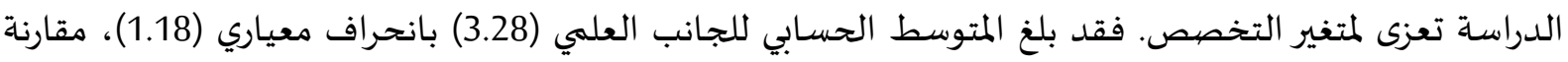
بالمتوسط الحسابي للإنساني (4.36) وانحراف معياري (890.) حيث قدرت قيمة "ت" (450.). وهي غير دالة إحصائيا عند مستوى الدلالة (0.05).

وتعزو الباحثة عدم وجود فروق بين اتجاهات أعضاء هيئة التدريس باختلاف تخصصياتهم نظراً لمناسبة

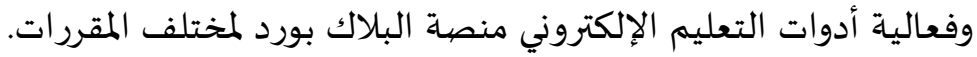
ثالثاً: التعرف على إذا ما كانت هناك فروق ذات دلاله التهات إحصائية عند (0.05) بين استجابات أفراد عينة

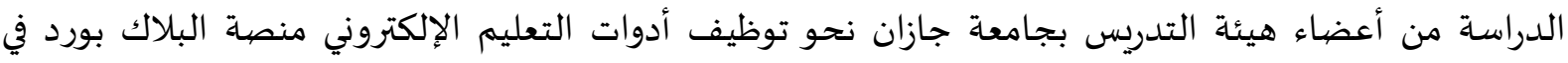
العملية التعليمية باختلاف متغير (الرتبة العلمية)، تم استخدام تحليل التباين الأحادي الاتجاه(One-Way-Anova)

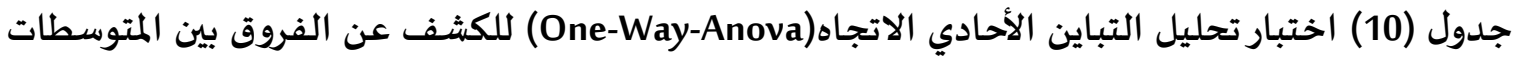
لاستجابات أفراد عينة الدراسة باختلاف متغير (الرتبة العلمية).

\begin{tabular}{|c|c|c|c|c|c|c|}
\hline مستوى الدلالة & الدلالة & قيمة ف & الانحراف & المتوسطات & العدد & الفئات \\
\hline \multirow{3}{*}{ غند عير دالة } & \multirow{3}{*}{0.405} & \multirow{3}{*}{0.360} & 1.011 & 3.09 & 5 & أستاذ مشـارك \\
\hline & & & .987 & 4.39 & 55 & أستاذ مسـاعد \\
\hline & & & .973 & 4.30 & 30 & محاضر \\
\hline
\end{tabular}

نلاحظ من الجدول (10) لا توجد فروق ذات دلالة إحصائية لمحاور الدراسة بين أفراد العينة تعزى لمتغير الرتبة العلمية. حيث قدرت قيمة "ف " ب (0.360) بدلالة معنوية قيمتها (0.405) وهي غير داله إحصائياً لأنها أكبر من مستوى الدلالة(0.05)، وهذا يتفق الدراسات السابقة. التوصيات والمقترحات: في ضوء نتائج الدراسة توصي الباحثة وتقترح بـ 1- ضرورة تشجيع أعضاء هيئة التدريس والطلاب للاستفادة من كافة أدوات التقييم المتاحة للتعليم الإلكتروني

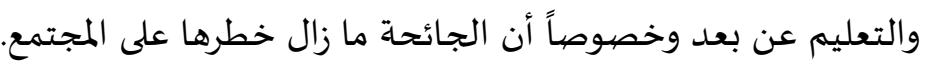

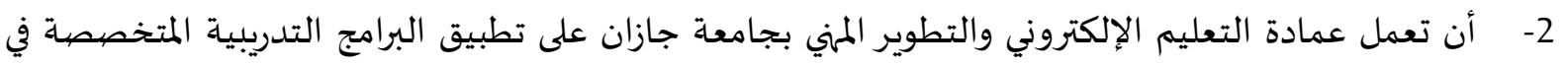

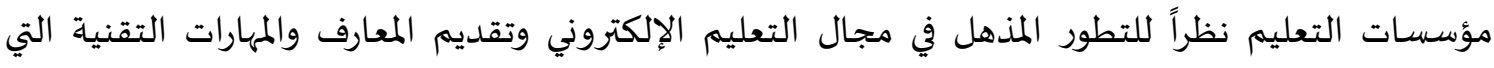
يحتاجها أعضاء هيئة التدريس والطلاب. 3- رفع التقارير من قبل وحدات التعليم الإلكتروني بالكليات واتخاذ القرارات المناسبة. 
4- استخدام استراتيجيات التعلم النشط المتاحة من خلال منصة البلاك بورد وتنوع تقديم المادة التعليمية للمتعلم مما يؤدي للفائدة الكاملة له وزيادة التحصيل الدراسي. 5- الدعم والتدريب لأعضاء هيئة التدريس بجامعة جازان لرفع كفاءة الاداء وجودة المخرج التعليمي.

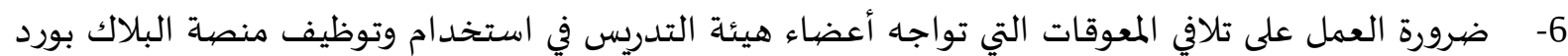

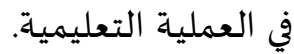
7- اجراء دراسات و بحوث حول فعالية استخدام أدوات التقويم بمنصة البلاك ومدى كفاءهها في قياس مهارات

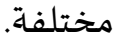
8- دعم التعليم الإلكتروني من قبل الادارات والمؤسسات التعليمية. قائمة المراجع

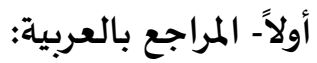
- البلاصي، رباب عبدالمقصود، (2016)." اتجاهات أعضياء هيئة التدريس بجامعة حائل نحو استخدام نظام إدارة

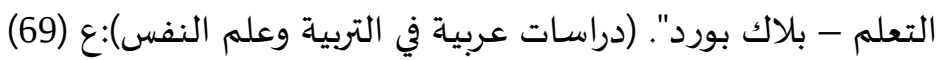

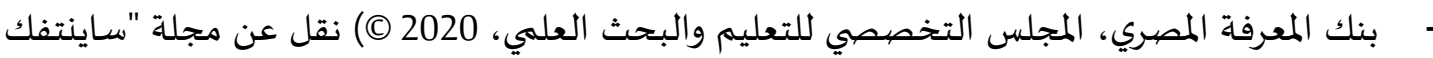
أمريكان"، التابعة لمجموعة نيتشر للنشر. https://www.scientificamerican.com/arabic/articles/news/distance-learning-versus-covid19/ - الجراح، عبد المهدي علي (2011)."اتجاهات طلبة الجامعة الاردنية نحو استخدام برمجة بلاك بورد في تعلمهم،

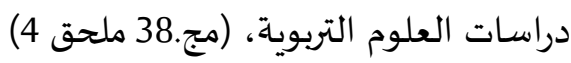
- الجنزوري، عباس عبدالعزيز.(2017) "اتجاهات اعضياء هيئة التدريس نحو توظيف أدوات التقويم الالكتروني

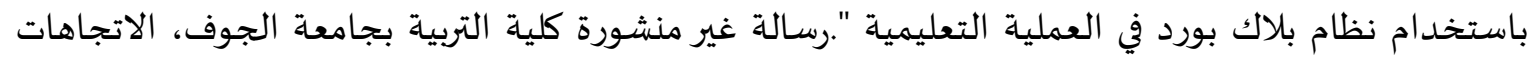

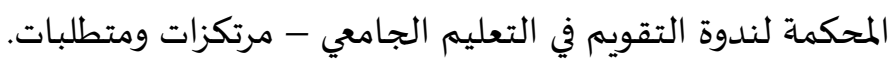

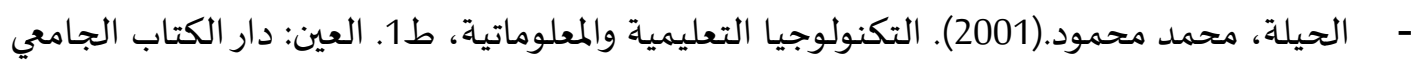

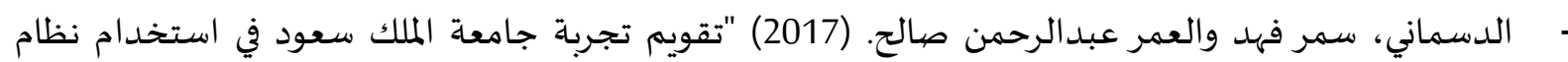

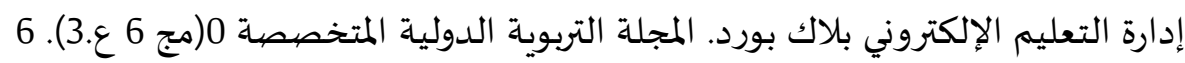
الرشيدي، حمد بن عايض.(2016)" الاحتياجات التدرببية لاستخدام نظام إدارة التعلم البلاك بورد (Black (Board

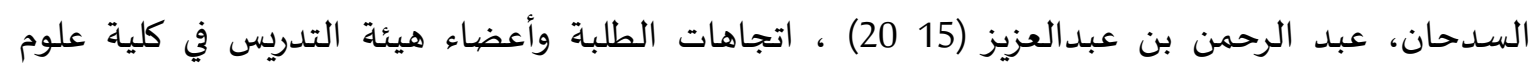
الحاسب والمعلومات جامعة الإمام محمد بن سعود نحو استخدام نظام إدارة التعلم الإلكتروني بلاك بوريل بورد

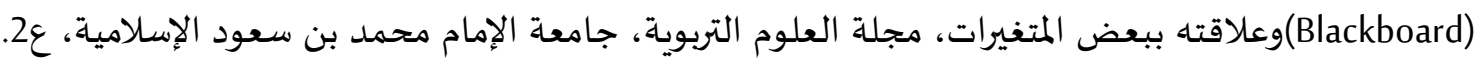

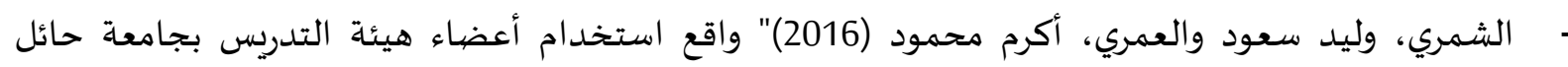

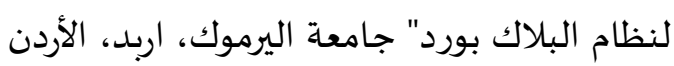
الشهري، أمل ظافر ومحمد، لمياء جلال (2014)" فاعلية برنامج تدريبي لتدريب طالبات كلية التربية جامعة

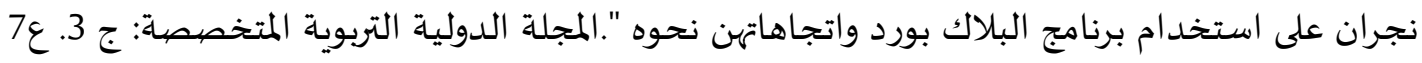


عبد الحميد واخرون (2013). "استخدام نظام التعليم الإلكتروني بلاك بورد في تدريب الطلاب المعلمين بكلية

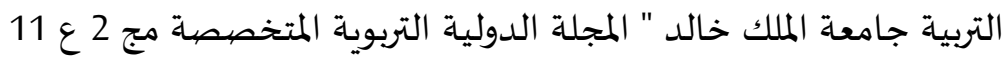

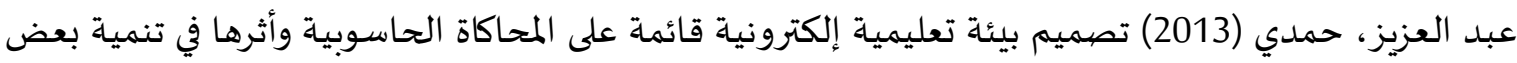
مهارات الأعمال المكتبية وتحسين مهارات التعلم لدى طلاب المدارس الثانوية التجارية. المجلة الأردنية في العلوم

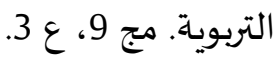

عقل، مجدي وخميس، محمد وأبو شقير، محمد (2012). تصميم بيئة تعليمية إلكترونية لتنمية مهارات تصميم

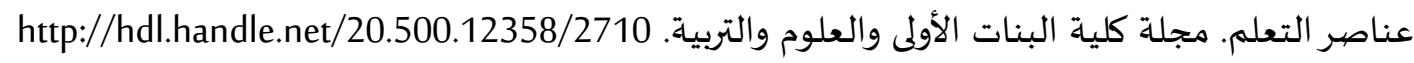
الغامدي، منى سعد وعافشي، ابتسام عباس، (2018). " فاعلية بيئة تعليمية إلكترونية قائمة على التعلم

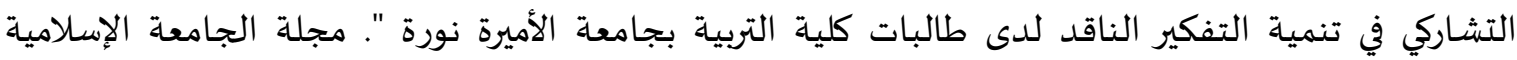

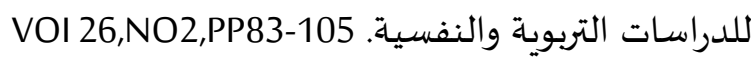
الغريب، إسماعيل، زاهر (2009). المقررات الإلكترونية. تصميمها - إنتاجها - نشرها - تطبيقها- تقوها ، القاهرة.

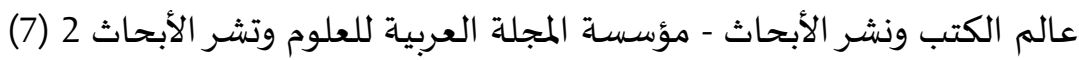

الغريب، إسماعيل. زاهر.(2001)، تكنولوجيا المعلومات وتحديث التعليم، عالم الكتب للنشر، المعاد القاهرة. 22. فتح الله، مندور عبد السلام (2019).تطبيقات استخدام الحاسب والإنترنت في التعليم. دار النشر الدولي. ط:(1).

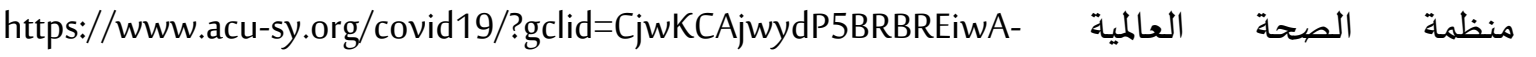
qrCGorxiHB8wN8cBdqdJM0aym28IlfOtRzooxA1yJmgRiT6P6v8bA694RoCBycQAvD_BwE هنداوي، اسامة سعيد، حمادة محمد، محمود، إبراهيم يوسف (2009) تكنولوجيا التعليم والمستحدثات

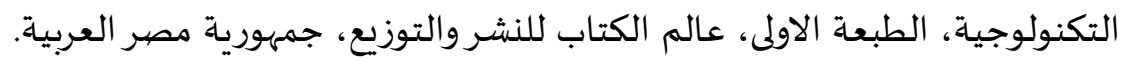

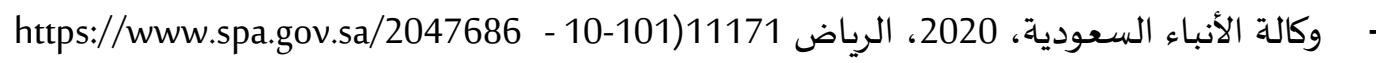

ثانياً- المرجع بالإنجليزية:

- Beatty, B. \& Ulasewicz, C. (2006). Online Teaching and Learning in Transition: Faculty Perspectives on Moving from Blackboard to Moodle Learning Management System. TechTrends, 50(4), pp. 36-47. the

- Chou, S., Liu, C. (2005).Learning effectiveness in a Web-based virtual learning environment: a learner control perspective, Journal of Computer Assisted Learning, 21.(1)

- Nitko , J. (2001). Educational Assessment of Students (3ed Ed.). Upper Saddle River, New Jersey.prentice Hall/ Merril Education.. https://docs.google.com/forms /d/e/1FAlpQLSev5OqsuP9s77YoahgJUX8XwCDvPf5u7kbx8y6tKqS4Ao5Ppw/viewform?usp=sf_link 
المجلة العربية للعوم ونثر الأبحاث ـ مجلة العوم التريوية والنفسية ـ المجلد الرابع ـ العدل السابع والثلاثون ـ أكتوير 2020م

\begin{tabular}{|c|c|c|c|c|c|c|c|c|c|c|c|c|c|c|c|c|c|c|c|c|}
\hline \multirow{2}{*}{ 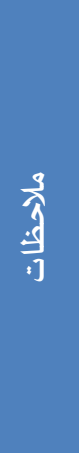 } & \multicolumn{8}{|c|}{ الأنشطة والأدوات التي تم تفعيلها على نظام بلاك بورد } & \multicolumn{3}{|c|}{ علدد حضيور } & \multicolumn{2}{|c|}{ المتحتدل المعليمي } & \multicolumn{2}{|c|}{ المحاضيرة } & \multicolumn{2}{|c|}{ لموعد لمبرات } & \multirow{2}{*}{ رقبم } & \multirow{2}{*}{ المقرر } & \multirow[b]{2}{*}{$\hat{r}$} \\
\hline & 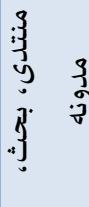 & 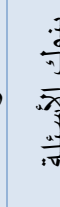 & 武 & 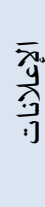 & 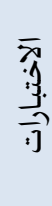 & $\frac{\overline{3}}{9}$ & $\begin{array}{l}\overline{7} \\
3 \\
3 \\
\overline{3} \\
\overline{3}\end{array}$ & 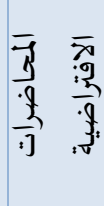 & $\begin{array}{l}3 \\
3 \\
3 \\
y \\
3\end{array}$ & $\frac{5}{2}$ & 霌 & 芑 & '] & . & .3. & & $\begin{array}{l}\text { og. } \\
\text { g } \\
y \\
3\end{array}$ & & & \\
\hline & & & & & & & & & & & & & & & & & & & & \\
\hline & & & & & & & & & & & & & & & & & & & & \\
\hline & & & & & & & & & & & & & & & & & & & & \\
\hline
\end{tabular}

